\title{
Engineering Strategies in
} Microorganisms for the Enhanced Production of Squalene: Advances, Challenges and Opportunities

\author{
Nisarg Gohil ${ }^{1}$, Gargi Bhattacharjee ${ }^{1}$, Khushal Khambhati ${ }^{1}$, Darren Braddick ${ }^{2}$ and \\ Vijai Sing ${ }^{1 *}$
}

${ }^{1}$ School of Biological Sciences and Biotechnology, Institute of Advanced Research, Koba Institutional Area, Gandhinagar, India, ${ }^{2}$ Department of R\&D, Cementic S. A. S., Genopole, Paris, France

\section{OPEN ACCESS}

Edited by:

Pablo Carbonell,

University of Manchester

United Kingdom

Reviewed by:

Tessa Moses,

University of Edinburgh,

United Kingdom

Fani Mantzouridou,

Aristotle University of Thessaloniki,

Greece

*Correspondence:

Vijai Singh

vijaisingh15@gmail.com;

vijai.singh@iar.ac.in

Specialty section:

This article was submitted to

Synthetic Biology,

a section of the journal

Frontiers in Bioengineering and

Biotechnology

Received: 16 January 2019

Accepted: 01 March 2019

Published: 22 March 2019

Citation:

Gohil N, Bhattacharjee G,

Khambhati K, Braddick D and Singh V (2019) Engineering Strategies in

Microorganisms for the Enhanced

Production of Squalene: Advances,

Challenges and Opportunities.

Front. Bioeng. Biotechnol. 7:50. doi: 10.3389/fbioe.2019.00050
The triterpene squalene is a natural compound that has demonstrated an extraordinary diversity of uses in pharmaceutical, nutraceutical, and personal care industries. Emboldened by this range of uses, novel applications that can gain profit from the benefits of squalene as an additive or supplement are expanding, resulting in its increasing demand. Ever since its discovery, the primary source has been the deep-sea shark liver, although recent declines in their populations and justified animal conservation and protection regulations have encouraged researchers to identify a novel route for squalene biosynthesis. This renewed scientific interest has profited from immense developments in synthetic biology, which now allows fine-tuning of a wider range of plants, fungi, and microorganisms for improved squalene production. There are numerous naturally squalene producing species and strains; although they generally do not make commercially viable yields as primary shark liver sources can deliver. The recent advances made toward improving squalene output from natural and engineered species have inspired this review. Accordingly, it will cover in-depth knowledge offered by the studies of the natural sources, and various engineering-based strategies that have been used to drive the improvements in the pathways toward large-scale production. The wide uses of squalene are also discussed, including the notable developments in anti-cancer applications and in augmenting influenza vaccines for greater efficacy.

Keywords: squalene, metabolic engineering, fermentation, biosynthesis, production, synthetic biology, antioxidant, anti-aging

\section{INTRODUCTION}

Squalene $\left(\mathrm{C}_{30} \mathrm{H}_{50}\right)$, an intermediate of cholesterol biosynthesis, is a naturally occurring highly unsaturated triterpenic hydrocarbon compound that forms solely via the mevalonic acid (MVA) or 2-C-methyl-D-erythritol 4-phosphate (MEP) pathways (Spanova and Daum, 2011; Popa et al., 2015; Rani et al., 2018). It was first described and identified in 1916 in deep-sea shark (Squalus spp.) liver by a Japanese chemist Mitsumaru Tsujimoto, hence the name "squalene" (Tsujimoto, 1916). Since its discovery, shark liver oil has been the largest source of squalene. A wide range of microorganisms including yeast such as Saccharomyces cerevisiae (Mantzouridou and Tsimidou, 2010) and Torulaspora delbrueckii (Bhattacharjee et al., 2001), fungus Aurantiochytrium sp. (Jiang et al., 2004; Nakazawa et al., 2014; Pora et al., 2014), Euglena (Anding et al., 1971), archaea 
Halobacterium cutirubrum, and several other species have the natural ability to produce squalene. Apart from sources of microbial origin, a number of reports have described the production of squalene from some plants, predominantly amaranth (Lyon and Becker, 1987; Czaplicki et al., 2011; Naziri et al., 2011b; Rosales-García et al., 2017b) and olive (Gutfinger and Letan, 1974; Frega et al., 1992; Nenadis and Tsimidou, 2002; Beltrán et al., 2016). As far as both plant and microbial sources are concerned, productivity still remains a major issue for scale-up, thereby, limiting their use as sources in industrial and biomedical applications (Spanova and Daum, 2011; Lozano-Grande et al., 2018).

In humans, squalene is one of the major components of sebum (12\%), epidermis $(<0.5 \%)$, and surface lipids (10\%) (Nicolaides, 1974). It is synthesized by the liver and secreted largely from the sebaceous glands (Popa et al., 2015). The amount of secreted squalene ranges from 125 to $475 \mathrm{mg} / \mathrm{day}$, depending upon the individuals and their diet (Nikkari et al., 1974). According to the clinical research data, about $60-85 \%$ of the total orally administrated squalene is absorbed and distributed efficiently to different tissues (Gabás-Rivera et al., 2014), namely the skin where it plays a salient role as an antioxidant to protect against the free radicals and environmental oxidative stress (Kohno et al., 1995). In most cases, after the age of 30, the concentration of squalene starts to decline (Popa et al., 2015). Therefore, it is preferable to supply exogenous squalene (about $500 \mathrm{mg} /$ day) for maintaining a healthy lifestyle (Günes, 2013).

Squalene has been known to play diverse biological roles as an anti-oxidant (Amarowicz, 2009; Günes, 2013), anti-cancer agent (Kim and Karadeniz, 2012; Günes, 2013), age defyer (Huang et al., 2009; Popa et al., 2015), chemopreventive agent (Aioi et al., 1995; Budiyanto et al., 2000; Smith, 2000), antibacterial agent (Kopicová and Vavreinová, 2007; Popa et al., 2015), adjuvant for vaccines and drug carrier (Del Giudice et al., 2006; Pasquale et al., 2015), and detoxifier (Kim and Karadeniz, 2012; Ivanova et al., 2015) among others. Thus, it is a favored choice in pharmaceuticals, cosmetic industries, and food supplements (Popa et al., 2015; Lozano-Grande et al., 2018). The role of squalene is not just confined to these applications, but it is also a precursor to thousands of bioactive molecules, including steroids and hopanoids. Consequently, many chemical, food, cosmetic, and pharmaceutical industries have started to use squalene extensively. Over the last decade, global squalene demand has increased and gained much public and scientific attention. In 2014, the global squalene market demand was about 2.67 kilotons (Rosales-Garcia et al., 2017a), with a projected value of 241.9 million USD by 2022, with major revenues expected from the personal care and cosmetic products (Global Market

\footnotetext{
Abbreviations: AACT, Acetoacetyl-CoA thiolase; DMAPP, Dimethylallyl diphosphate; DXP, 1-deoxy-D-xylulose-5-phosphate; FPP, Farnesyl pyrophosphate; FPS, Farnesyl pyrophosphate synthase; GA3P, Glyceraldehyde3-phosphate; GPP, Geranyl diphosphate; HMBPP, 4-hydroxy-3-methyl-but2-enylpyrophosphate; HMGR, HMG-CoA reductase; HMGS, 3-hydroxy-3methylglutaryl-CoA synthase; IDI, Isopentenyl diphosphate isomerase; IPP, Isopentenyl pyrophosphate; MEP, 2-C-methyl-d-erythritol 4-phosphate; MVA, Mevalonate; SHC, Squalene hopene cyclase; SQE, Squalene epoxidase; SQS, Squalene synthase; DCW, Dry cell weight.
}

Insights, 2016). In order to fulfill this ever-increasing demand of squalene, a pressing need has arisen to produce squalene in a renewable and sustainable manner.

Rapid and remarkable advances in genetic engineering, metabolic engineering and synthetic biology approaches over the last few decades have facilitated the insertion of heterologous genes and editing of the genome of an organism, enabling successful attempts to produce innumerable molecules of industrial importance (Martin et al., 2009; Stephanopoulos, 2012; Singh, 2014; Jullesson et al., 2015). Lately, a number of microorganisms have been engineered by inserting a squalene biosynthetic pathway or by the modification of existing biosynthetic pathway for over-production of squalene (Ghimire et al., 2009; Katabami et al., 2015; Han et al., 2018; Wei et al., 2018).

This review discusses the various sources of squalene, and therein the positive and negative aspects of their utilization toward large-scale production. Furthermore, we describe the native biosynthetic pathways which are present in many microorganisms and how these pathways can be transformed or extended to convert the organisms into "cellular factories" for squalene production. We summarize recently developed strategies that can overproduce this commercially valuable molecule. Through the review, we also point out possible strategies that might help to resolve the obstacles faced in squalene biosynthesis. Lastly, we highlight the ways to exploit the biological roles of squalene and its applications in manufacturing a wide range of industrially and medically important products.

\section{NATURAL SOURCES OF SQUALENE}

The importance of squalene with regards to its properties and applications has attracted many industries and research groups to discover rich sources of squalene in nature. The hunt for the novel sources is not just limited to its accessibility but also to the feasibility and ease of extraction. The accessible squalene sources such as yeast, fungi, plants, and deep sea sharks are shown in Figure 1.

\section{Squalene From Shark Liver Oil}

Over the years, deep-sea shark liver oil has been the major natural source of squalene (Ronco and De Stéfani, 2013; Popa et al., 2015; Rosales-Garcia et al., 2017a). It is estimated that for producing 1 ton of squalene, it demands as many as about 3,000 sharks (Ciriminna et al., 2014). A single distillation under vacuum at a temperature of $200-230^{\circ} \mathrm{C}$ is required for recovering $>98 \%$ purified squalene from the liver oil (Ciriminna et al., 2014). Every year, approximately 100 million sharks are killed brutally for the purpose of shark finning (Tsoi et al., 2016), with most of it fulfilling the global demand of squalene for cosmetic industries (Ciriminna et al., 2014).

The long reproductive cycle and slow growth rate of sharks in tandem with the reckless fishing have taken a grave toll on their numbers, which now threatens to reach near extinction. This rapid depletion of shark populations is taking place at a lightning speed, far exceeding its recovery. In an attempt to conserve shark populations, numerous shark breeding and importing countries 


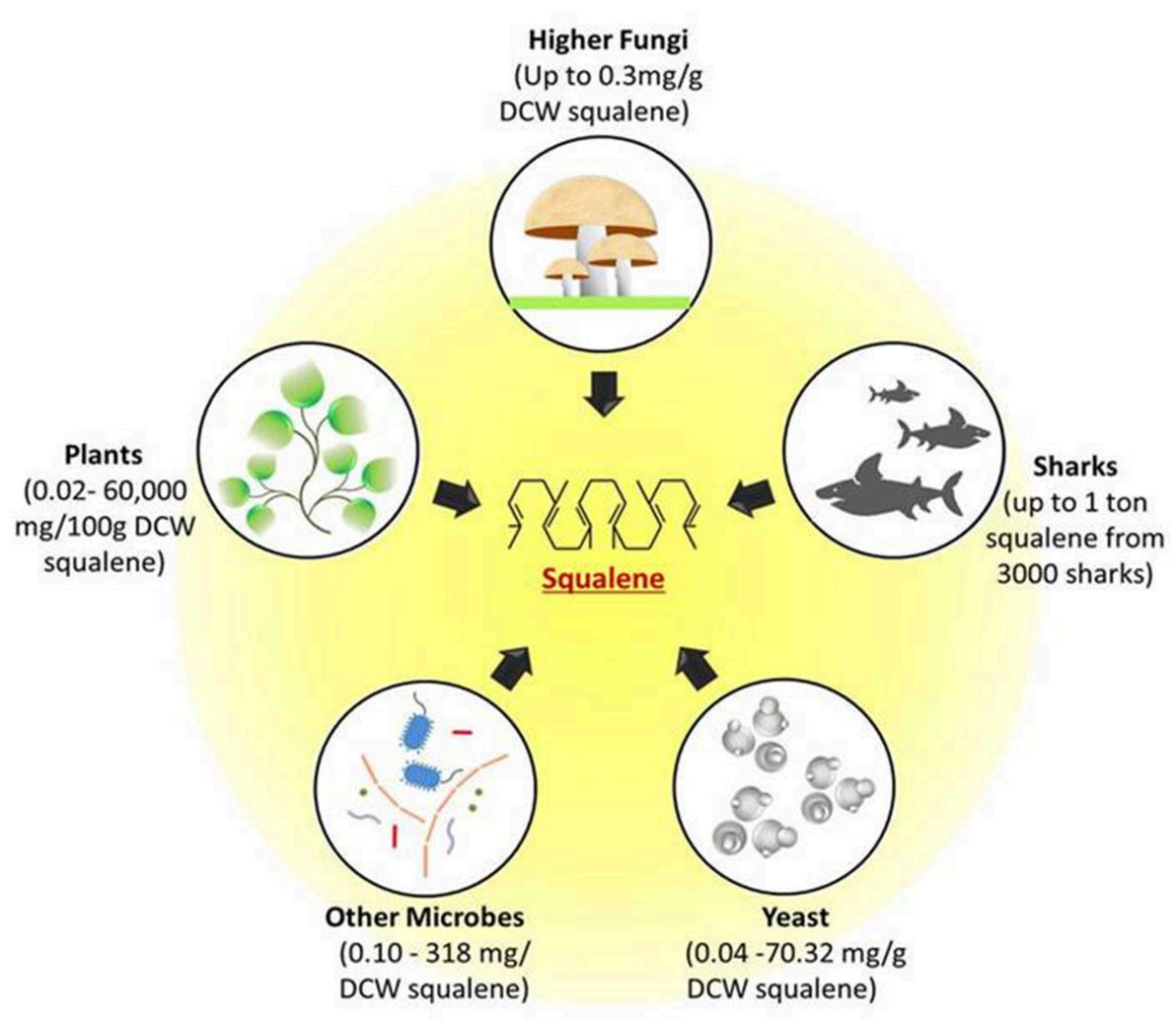

FIGURE 1 | Potential natural sources of squalene. Figure depicts the possible squalene sources ranging from unicellular microbes such as yeast and other bacterial cells to multicellular fungi, plants, and deep sea sharks. All these sources can produce squalene through mevalonate pathway. DCW, Dry cell weight.

such as the United States of America, Costa Rica, New Zealand, Taiwan, Australia, and those included in the European Union have banned shark killing and finning (Dulvy et al., 2008). Apart from that, considering the similarities that squalene share with the other lipid components present in shark liver oil, the process of its purification as a separate entity is cumbersome. Nowadays, oceans are heavily polluted with tons of trash, oil spills, fertilizers, pesticides, chemicals, plastics, heavy metals, organic and other persistent organic pollutants (POPs), which results from manmade ecocide (Seltenrich, 2015; Ramírez-García et al., 2018). These pollutants can still be recovered even after purification of squalene from the shark (Popa et al., 2014). Therefore, with the population and contamination concerns, it becomes an utmost necessity to pursue the extraction and production of squalene from improved and renewable sources.

\section{Squalene From Plants}

Besides shark liver oil, most plant oils contain a minute amount of squalene (Czaplicki et al., 2012). This phytosqualene has an edge over the shark squalene, in terms that it is highly stable, non-toxic, odorless, and colorless (Popa et al., 2014), favoring its use in cosmetic and pharmaceutical industries. Additionally, the plant based squalene has the capability to reduce the risk of different types of cancer by minimizing serum cholesterol levels (He et al., 2003). Phytosqualene was first found and extracted from olive oil (Thorbjarnarson and Drummond, 1935), and since then, the quest for alternatives is still in progress. Interestingly, amongst the known plant sources, olive oil (0.9-12.45 g/kg squalene; Giacometti and Milin, 2001) is the only source used for commercial purposes (Lozano-Grande et al., 2018), despite the fact that amaranth has the highest squalene content $(600 \mathrm{~g} / \mathrm{kg})$ of all the reported plant sources (Wejnerowska et al., 2013). The reason behind this is that the lipid content present in olives (6.6726.67\%) (United States Department of Agriculture, 2018a,b) is greater than the amaranth seeds (4.8-8.1\%) (Saunders and Becker, 1984; United States Department of Agriculture, 2018c), although the amount recovered is still insufficient to meet the global demands.

Rice bran, a co-product of the rice milling process also contains a good amount (318.9-320 mg/100 g) of squalene (Rukmini and Raghuram, 1991; Pokkanta et al., 2019). Palm oil has just 20-50 mg/100 g of squalene (Goh et al., 1985; Lau et al., 2005) but because of its large-scale production, it can be considered as an acceptable source of the squalene overall. Apart from this, avocado (34-37 mg/100 g squalene) (Gutfinger and Letan, 1974) has also been reported to contain a meager amount of squalene. Some nuts also contain small amounts of squalene, including brazil nut (145.8 mg/100 g) (Derewiaka et al., 2014), peanut (27.4-132.9 mg/100 g) (Frega et al., 1992; Tuberoso et al., 2007; Pokkanta et al., 2019), hazelnut (9.3-39.2 
mg/100 g) (Frega et al., 1992; Bada et al., 2004; Derewiaka et al., 2014), macadamia (7.2-38.3 mg/100 g) (Maguire et al., 2004; Wall, 2010; Derewiaka et al., 2014), pecan (20.8-29.8 mg/100 g) (Derewiaka et al., 2014; Fernandes et al., 2017), pistachio (5.5$22.6 \mathrm{mg} / 100 \mathrm{~g}$ ) (Derewiaka et al., 2014; Salvo et al., 2017), cashew (11.6 mg/100 g) (Derewiaka et al., 2014), almond (1.3-9.6 mg/100 g) (Liu et al., 1976; Fernandes et al., 2017), and walnut (0.09-0.94 mg/100 g).

Seeds such as ginseng (514-569 mg/100 g) (Beveridge et al., 2002), soybean (3-22 mg/100 g) (Gutfinger and Letan, 1974; Frega et al., 1992; Maguire et al., 2004; Naziri et al., 2011b; Pokkanta et al., 2019), sunflower seed (0-19 mg/100 g) (Tuberoso et al., 2007; Naziri et al., 2011b), sesame seed (57.2-60.7 $\mathrm{mg} / 100 \mathrm{~g}$ ) (Pokkanta et al., 2019), coriander seed (45.1 mg/100 g) (Pokkanta et al., 2019), pumpkin seed (260-523 mg/100 g) (Tuberoso et al., 2007; Czaplicki et al., 2011; Naziri et al., 2011b), flaxseed (1.0-4.2 mg/100 g) (Tanska et al., 2016), rape seed (43.7 mg/100 g) (Tuberoso et al., 2007), grape seed (10.2$16.2 \mathrm{mg} / 100 \mathrm{~g}$ ) (Frega et al., 1992; Wen et al., 2016), cottonseed (2.7-9.1 mg/100 g) (Gutfinger and Letan, 1974; Liu et al., 1976), and Rosaceae (0-0.2 mg/100 g) (Matthaus and Özcan, 2014) have also been reported to contain squalene. Furthermore, presence of squalene in some unconventional oil sources such as apricot kernels (12-43 mg/100 g) (Rudzinska et al., 2017) and borage $(22 \mathrm{mg} / 100 \mathrm{~g}$ ) (Czaplicki et al., 2011) has also been explored.

In the industrial refining of plant oils, a step called "deodorizing" is usually employed to remove the impurities. At the end of this step, many bioactive compounds such as squalene, tocopherols, phytosterols, and fatty acids accumulate as byproducts, commonly called as "deodorizer distillate" (Popa et al., 2015; Sherazi and Mahesar, 2016). Though it is a waste product of the refining process, it comprises up to $80 \%$ squalene (Popa et al., 2015), making it a better alternative over the crude plant oil for production of squalene. Olive oil contains about $0.99-12.45 \mathrm{~g} / \mathrm{kg}$ squalene (Giacometti and Milin, 2001), whereas the deodorizing distillates of olive oil contain 100-300 g/kg squalene (Naziri et al., 2011b). Similarly, soybean, sunflower, canola, and palm fatty acid distillates encompass about 18-55, 43-45, 30-35, and 2-13 g/kg of squalene, respectively (Dumont and Narine, 2007; Naziri et al., 2011b; Naz et al., 2014). In a similar context, wine lees from wineries can be diverted toward squalene production, thereby improving valorization. A yield of $0.6 \pm 0.08 \mathrm{~g} / \mathrm{kg}$ of squalene can be obtained using dry lees (Naziri et al., 2012). The various plant sources and their reported squalene contents are summarized in Table 1.

In spite of holding a good amount of squalene, plants cannot be considered as an ideal source of squalene because some plants are strictly seasonal and the amount of squalene varies greatly geographically. Plants critically require the appropriate temperature and humidity, favorable climatic conditions, soil texture, scheduled irrigation, steady rainfall, fertilizer, and pest management. Aside from the challenges that have been discussed, the process of cultivation is in itself labor intensive and correspondingly the amount of squalene produced from plant sources is not sufficient to fulfill the increasing demand of squalene.
TABLE 1 | Plant sources of squalene.

\begin{tabular}{|c|c|c|}
\hline Plant source & $\begin{array}{l}\text { Concentration } \\
\text { (mg/100 g DCW) }\end{array}$ & Reference \\
\hline \multicolumn{3}{|l|}{ OILS } \\
\hline \multirow[t]{6}{*}{ Amaranth } & 60,000 & Wejnerowska et al., 2013 \\
\hline & 46,000 & Rosales-García et al., 2017b \\
\hline & $2,000-8,000$ & He and Corke, 2003 \\
\hline & $1,040-6,980$ & Lyon and Becker, 1987 \\
\hline & 6,960 & Czaplicki et al., 2011 \\
\hline & 5,220 & Beltrán et al., 2016 \\
\hline \multirow[t]{8}{*}{ Olive } & $99-1,245$ & Grigoriadou et al., 2007 \\
\hline & $80-1,200$ & Lanzón et al., 1994 \\
\hline & $250-925$ & Beveridge et al., 2002 \\
\hline & 110-839 & Czaplicki et al., 2011 \\
\hline & $375-652$ & Nenadis and Tsimidou, 2002 \\
\hline & 564 & Frega et al., 1992 \\
\hline & $170-460$ & Grigoriadou et al., 2007 \\
\hline & $342-450$ & Manzi et al., 1998 \\
\hline Ginseng seed & $514-569$ & Beveridge et al., 2002 \\
\hline \multirow[t]{3}{*}{ Pumpkin seed } & 523 & Czaplicki et al., 2011 \\
\hline & 352.9 & Tuberoso et al., 2007 \\
\hline & $260-350$ & Naziri et al., 2011b \\
\hline \multirow[t]{2}{*}{ Rice bran } & 320 & Rukmini and Raghuram, 1991 \\
\hline & 318.9 & Pokkanta et al., 2019 \\
\hline Brazil nut & 145.8 & Derewiaka et al., 2014 \\
\hline \multirow[t]{3}{*}{ Peanuts } & 132.9 & Pokkanta et al., 2019 \\
\hline & 127.6 & Tuberoso et al., 2007 \\
\hline & 27.4 & Frega et al., 1992 \\
\hline White sesame seed & 60.7 & Pokkanta et al., 2019 \\
\hline Black sesame seed & 57.2 & Pokkanta et al., 2019 \\
\hline \multirow[t]{2}{*}{ Palm } & $20-50$ & Goh et al., 1985 \\
\hline & 43.3 & Lau et al., 2005 \\
\hline Coriander seed & 45.1 & Pokkanta et al., 2019 \\
\hline Apricot kernel & $12.6-43.9$ & Rudzinska et al., 2017 \\
\hline \multirow[t]{3}{*}{ Hazelnut } & $9.3-39.2$ & Bada et al., 2004 \\
\hline & 27.9 & Frega et al., 1992 \\
\hline & 25.7 & Derewiaka et al., 2014 \\
\hline \multirow[t]{3}{*}{ Macadamia nut } & 38.3 & Derewiaka et al., 2014 \\
\hline & 18.5 & Maguire et al., 2004 \\
\hline & $7.2-17.1$ & Wall, 2010 \\
\hline Avocado & $34.1-37.0$ & Gutfinger and Letan, 1974 \\
\hline \multirow[t]{3}{*}{ Corn } & 33.8 & Tuberoso et al., 2007 \\
\hline & 30.6 & Frega et al., 1992 \\
\hline & $10-17$ & Naziri et al., 2011b \\
\hline \multirow[t]{2}{*}{ Pecan } & 29.8 & Fernandes et al., 2017 \\
\hline & 20.8 & Derewiaka et al., 2014 \\
\hline \multirow[t]{2}{*}{ Pistachio } & $5.5-22.6$ & Salvo et al., 2017 \\
\hline & 8.2 & Derewiaka et al., 2014 \\
\hline Borage & 22 & Czaplicki et al., 2011 \\
\hline \multirow[t]{4}{*}{ Soybean } & 22 & Maguire et al., 2004 \\
\hline & $3-20$ & Naziri et al., 2011b \\
\hline & 18.4 & Pokkanta et al., 2019 \\
\hline & $12.5-14.3$ & Gutfinger and Letan, 1974 \\
\hline
\end{tabular}

(Continued) 
TABLE 1 | Continued

\begin{tabular}{|c|c|c|}
\hline Plant source & $\begin{array}{l}\text { Concentration } \\
\text { (mg/100 g DCW) }\end{array}$ & Reference \\
\hline & 9.9 & Frega et al., 1992 \\
\hline \multirow[t]{2}{*}{ Sunflower seed } & $0-19$ & Naziri et al., 2011b \\
\hline & 17 & Tuberoso et al., 2007 \\
\hline Rape seed & 43.7 & Tuberoso et al., 2007 \\
\hline \multirow[t]{2}{*}{ Grape seed } & $10.2-16.2$ & Wen et al., 2016 \\
\hline & 14.1 & Frega et al., 1992 \\
\hline Cashew & 11.6 & Derewiaka et al., 2014 \\
\hline \multirow[t]{2}{*}{ Almond } & 9.6 & Fernandes et al., 2017 \\
\hline & 1.3 & Liu et al., 1976 \\
\hline \multirow[t]{2}{*}{ Cotton-seed } & 9.10 & Gutfinger and Letan, 1974 \\
\hline & 2.78 & Liu et al., 1976 \\
\hline Flaxseed & $1.0-4.2$ & Tanska et al., 2016 \\
\hline Coconut & 1.6 & Gutfinger and Letan, 1974 \\
\hline \multirow[t]{2}{*}{ Walnut } & 0.94 & Maguire et al., 2004 \\
\hline & 0.09 & Liu et al., 1976 \\
\hline Rosaceae seed & $0.02-0.29$ & Matthaus and Özcan, 2014 \\
\hline \multicolumn{3}{|l|}{ DISTILLATES } \\
\hline \multirow[t]{2}{*}{ Olive oil } & $10,000-30,000$ & Naziri et al., 2011b \\
\hline & 28,000 & Bondioli et al., 1993 \\
\hline \multirow[t]{3}{*}{ Soybean oil } & 5,500 & Dumont and Narine, 2007 \\
\hline & $1,800-3,500$ & Naziri et al., 2011b \\
\hline & 1,830 & Gunawan et al., 2008 \\
\hline Sunflower oil & $4,300-4,500$ & Naz et al., 2014 \\
\hline Canola oil & $3,000-3,500$ & Naz et al., 2014 \\
\hline \multirow[t]{2}{*}{ Palm fatty acid } & $200-1,300$ & Naziri et al., 2011b \\
\hline & 1,030 & Posada et al., 2007 \\
\hline Wine lees & 6,000 & Naziri et al., 2012 \\
\hline
\end{tabular}

$D C W$, dry cell weight.

\section{Squalene From Microorganisms}

Microorganisms are amongst the prominent natural sources of squalene. Even though they do not accumulate as much amount as the sharks and plants do, their fast and prodigious growth along with the ease to engineer make them a better alternative for squalene production. The well-studied eukaryotic model organism Saccharomyces cerevisiae (yeast) was reported to produce a small amount of squalene, up to $1.6 \mathrm{mg} / \mathrm{g}$ dry cell weight (DCW) (Mantzouridou and Tsimidou, 2010; Naziri et al., 2011a). A number of fungi such as Torulaspora delbrueckii (0.24 mg/g DCW) (Bhattacharjee et al., 2001), Aspergillus nidulans (0.3 mg/g DCW) (Goldberg and Shechter, 1978), Kluyveromyces lactis (Drozdíková et al., 2015), and industrial yeast Saccharomyces uvarum $(14.3 \mathrm{mg} / \mathrm{g}$ DCW) have the ability to produce squalene (Blagović et al., 2001).

A newly isolated oleaginous yeast strain Pseudozyma sp. JCC 207 is capable of producing squalene up to $340 \mathrm{mg} / \mathrm{L}$ (Chang et al., 2008). This yield is considerably better and is suitably high to be used for commercial squalene production. A number of microorganisms such as Euglena (Anding et al., 1971), Candida famata (Tsujiwaki et al., 1995), Rhodopseudomonas palustris (Xu et al., 2016) and archaea Halobacterium cutirubrum
(1 mg/g DCW) (Goldberg and Shechter, 1978) were also reported to store squalene. Marine bacteria such as Rubritalea squalenifaciens sp.nov. (15 mg/g DCW) (Kasai et al., 2007), $R$. spongiae sp.nov. (Yoon et al., 2007), R. tangerina sp.nov. (Yoon et al., 2007), and R. sabuli sp. nov. (Yoon et al., 2008) belong to the family Verrucomicrobiaceae are also known to accumulate squalene.

Apart from that, Pseudomonas sp. (Goldberg and Shechter, 1978; Uragami and Koga, 1986), Methylomonas methanolica (Goldberg and Shechter, 1978) and Methylococcus capsulatus (Goldberg and Shechter, 1978) were found to produce squalene up to $0.76,1.16,5 \mathrm{mg} / \mathrm{g}$ DCW, respectively. Some microalgae such as Schizochytrium mangrovei $(0.16 \mathrm{mg} / \mathrm{g})$ (Jiang et al., 2004), Aurantiochytrium sp. (0.57-0.72 mg/g DCW) (Li et al., 2009; Chen et al., 2010; Fan et al., 2010) and Botryococcus braunii (Banerjee et al., 2002; Uchida et al., 2015) can accumulate considerable amount of squalene.

Thraustochytrids are eukaryotic, marine squalene amassing microorganisms that can grow rapidly in harsh conditions when organic carbon is well furnished (Aasen et al., 2016). In a study conducted to screen and characterize squalene accumulating Aurantiochytrium sp. strains from the Hong Kong mangrove sites, the strain Aurantiochytrium sp. BR-MP4-A1 was found to produce the highest squalene titre $(2.46 \mathrm{~g} / \mathrm{L})$ after $72 \mathrm{~h}$ among all the tested isolates, whereas its squalene content extended up to $0.567 \mathrm{mg} / \mathrm{g}$ DCW following $36 \mathrm{~h}$ of incubation ( $\mathrm{Li}$ et al., 2009). Many studies have confirmed that Aurantiochytrium sp. could accumulate a considerable amount of squalene (Jiang et al., 2004; Chen et al., 2010; Fan et al., 2010; Kaya et al., 2011; Hoang et al., 2014, 2018; Nakazawa et al., 2014). In a patent (WO/2012/159979) registered for discovering a process for producing squalene from the microalgal species Thraustochytriales, claimed that by providing an enriched medium with vitamins $B_{12}, B_{1}$ and/or $\mathrm{B}_{6}$ at $30^{\circ} \mathrm{C}$ temperature, squalene titre could be obtained between 20 and $120 \mathrm{mg} / \mathrm{g}$ DCW (Pora et al., 2014). Including those discussed, a number of wild-type microorganisms and their reported squalene content are given in Table 2.

The level of squalene can be enhanced and improved in wide range of microorganisms by; (1) using fermentation with additionally optimized conditions (Chen et al., 2010; Fan et al., 2010; Nakazawa et al., 2012), (2) genetic manipulation or introduction of squalene producing gene(s) in native squalene biosynthesis pathways (Bunch and Harris, 1986; Singh et al., 2017, 2018; Valachovič and Hapala, 2017), and (3) addition of an inhibitor (e.g., terbinafine) that blocks the competitive pathway thus allowing squalene accumulation.

\section{SQUALENE BIOSYNTHETIC PATHWAY IN MICROORGANISMS}

Two major isoprenoids pathways have been discovered and used for the production of squalene. It can be either synthesized 
TABLE 2 | Wild-type microorganisms as a source of squalene.

\begin{tabular}{llll}
\hline Microorganism & \multicolumn{2}{c}{ Squalene } & Reference(s) \\
\cline { 2 - 3 } & Yield(mg/g DCW) & Titre(mg/L) & Mantzouridou and Tsimidou, 2010 \\
\hline Saccharomyces cerevisiae & $0.04-1.6$ & ND & Bhattacharjee et al., 2001 \\
Torulaspora delbrueckii & 0.24 & ND & Kaya et al., 2011 \\
Aurantiochytrium sp. 18 W-13a & 198 & 1,290 & Nakazawa et al., 2014 \\
Aurantiochytrium sp. Yonez 5-1 & 317.74 & 1073.66 & Li et al., 2009 \\
Aurantiochytrium sp. BR-MP4-A1 & 0.57 & ND & Jiang et al., 2004; Pora et al., 2014 \\
A. mangrovei & $0.16-120$ & ND & Goldberg and Shechter, 1978 \\
Aspergillus nidulans & 0.3 & ND & Goldberg and Shechter, 1978 \\
Halobacterium cutirubrum & 1 & ND & Goldberg and Shechter, 1978 \\
Methylococcus capsulatus & 5.5 & ND & Goldberg and Shechter, 1978 \\
Pseudomonas sp. & $0.10-0.76$ & ND & Goldberg and Shechter, 1978 \\
Methylomonas methanolica & 1.16 & ND & Kasai et al., 2007 \\
Rubritalea squalenifaciens sp. nov. & 15 & ND & Drozdíková et al., 2015 \\
Kluyveromyce lactis & $0.6 \mathrm{mg} / 10^{9}$ cells & ND & Chang et al., 2008 \\
Pseudozyma sp. JCC 207 & 70.32 & 340.52 & \\
\hline
\end{tabular}

DCW, dry cell weight; ND, no data.

via the MVA or the MEP pathway, where the latter is also sometimes referred to as the DXP (1-deoxy-D-xylulose-5phosphate) pathway, depending upon the organism in which the process is taking place. Prokaryotes such as bacteria and cyanobacteria possess the MEP pathway whereas eukaryotes comprising yeast, higher fungi, plants, animals and humans bear the MVA pathway for the synthesis of squalene.

As shown in Figure 2, the MVA pathway starts with the condensation of three units of acetyl-CoA to form 3-hydroxy3-methylglutaryl-CoA (HMG-CoA) via acetoacetyl-CoA, in consecutive reactions catalyzed by the enzymes acetoacetylCoA thiolase (AACT) and HMG-CoA synthase (HMGS). Later, HMG-CoA is reduced to MVA in presence of cofactor NADPH by HMG-CoA reductase (HMGR) and then MVA is subsequently phosphorylated twice by enzymes MVA kinase and phospho-MVA kinase to form MVA-5-diphosphate. Following that, decarboxylation of MVA-5-diphosphate takes place in presence of adenosine triphosphate (ATP) to form isopentyl diphosphate (IPP). Next, IPP interconverts into dimethylallyl diphosphate (DMAPP) through a reaction catalyzed by IPP isomerase (IDI). Condensation of both molecules, IPP and DMAPP, by farnesyl diphosphate synthase (FPS) results in geranyl diphosphate (GPP), which is followed by a condensation reaction converting GPP to a 15-carbon isopentyl block unitFPP (farnesyl pyrophosphate). Eventually, two molecules of FPP are used to synthesize squalene by an NADPH mediated reaction catalyzed by squalene synthase (SQS, encoded by ERG9). The pathway then continues onward to synthesize sterols (Ghimire et al., 2016; Mao et al., 2017).

The MEP pathway begins with the condensation of glyceraldehyde-3-phosphate (GA3P) and pyruvate to build DXP that is catalyzed by DXP synthase (DXS). DXP then undergoes reduction to form MEP by DXP reductoisomerase (DXR) or its isozyme DRL (DXR-like). MEP is subsequently transformed into IPP and DMAPP in the subsequent steps by a series of enzymes. The remaining steps from IPP to FPP are identical to the MVA pathway. Unlike the MVA pathway, MEP pathway does not usually produce squalene, but advances in metabolic engineering and synthetic biology techniques have made it possible to design and introduce a heterologous SQS gene(s) that can extend the MEP pathway to produce squalene (Ghimire et al., 2009; Katabami et al., 2015).

\section{FERMENTATION OPTIMIZATION FOR SQUALENE PRODUCTION}

A wide range of chemicals and bioactive molecules have been identified in the organisms that are produced as an intermediate product in the pathways (Sanchez and Demain, 2008; Keasling, 2010; Chubukov et al., 2016; Panchasara et al., 2018). In order to elevate the industrial scale production of valuable products, fermentation technology uses the adaptability of the natural pathways to produce a desired molecule from the organisms by utilizing cheaper sources of substrates (Saha, 2003). In this way, the input cost can be minimized for large-scale production through the use of particular strains in controlled environments.

Several groups have demonstrated the ability of S. cerevisiae to produce squalene, although the amount produced by this strain is considerably low $(0.041 \mathrm{mg} / \mathrm{g}$ of biomass). Therefore, it is not a suitable candidate for squalene production unless the fermentation conditions are optimized (Bhattacharjee et al., 2001; Fornairon-Bonnefond et al., 2002). In an evaluation of the potential of baker's yeast $S$. cerevisiae and T. delbrueckii for fermentative squalene production, a higher amount of squalene $(237.25 \mu \mathrm{g} / \mathrm{g} \mathrm{DCW})$ was achieved in T. delbrueckii as compared to $S$. cerevisiae $(41.16 \mu \mathrm{g} / \mathrm{g} \mathrm{DCW})$. This demonstrates that $T$. delbrueckii could be used for commercial squalene production (Bhattacharjee et al., 2001). Optimizing the effect of oxygen supply, inoculum size, and fermentation time on $S$. cerevisiae BY4741 and EGY48 strains revealed that weaker oxygen supply is 
A

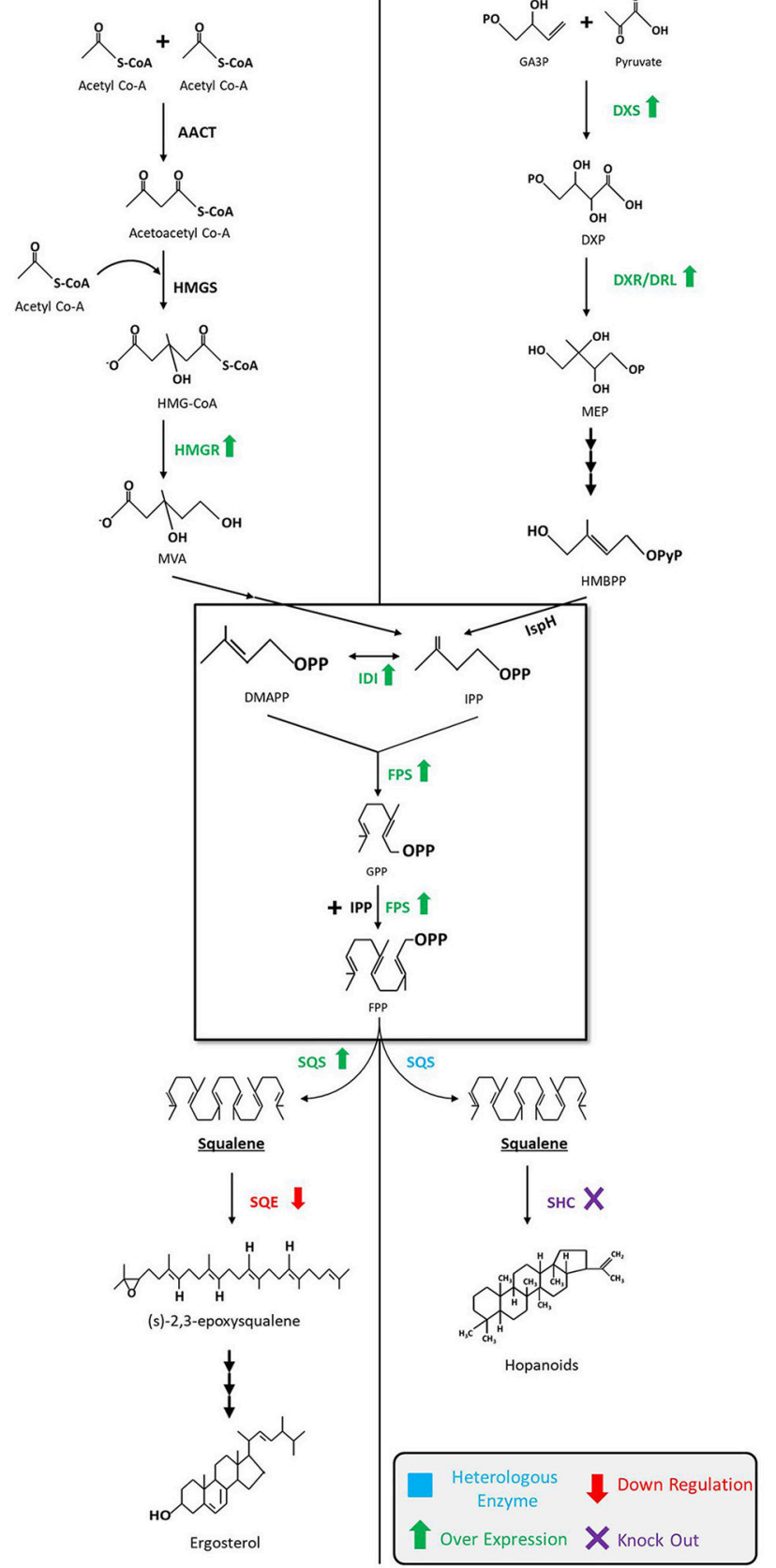

FIGURE 2 | Squalene biosynthetic pathways and production strategies. (A) Squalene biosynthesis via MVA pathway in yeast, fungi, and algae. The engineering strategies for enhanced squalene production are as follows: overexpression of HMGR (Polakowski et al., 1998; Tokuhiro et al., 2009; Mantzouridou and Tsimidou, 2010; Dai et al., 2012, 2014; Zhuang and Chappell, 2015; Rasool et al., 2016a,b; Kwak et al., 2017; Paramasivan and Mutturi, 2017; Han et al., 2018; Huang et al., 2018; Wei et al., 2018) and SQS (Dai et al., 2014; Zhuang and Chappell, 2015; Rasool et al., 2016a,b), downregulation of SQE (Garaiová et al., 2014; Hull et al., 2014; Zhuang and Chappell, 2015; Rasool et al., 2016a,b; Han et al., 2018) in yeast; downregulation of SQE in algae (Kajikawa et al., 2015). (B) Squalene biosynthesis via MEP pathway in bacteria. The engineering strategies for the enhanced squalene production are as follows: overexpression of DXS (Ghimire et al., 2009), IDI (Ghimire et al., 2009; Katabami et al., 2015) and FPS (Katabami et al., 2015), introduction of heterologous squalene producing enzyme(s) (Ghimire et al., 2009; Furubayashi et al., 2014a; Katabami et al., 2015; Pan et al., 2015) in E. coli; overexpression of DXS and IDI, and the introduction of FPS into Synechococcus elongatus (Choi et al., 2016); deletion of SHC in Synechocystis (Englund et al., 2014) and Rhodopseudomonas palustris (Xu et al., 2016). MVA, mevalonate; MEP, 2-C-methyl-d-erythritol 4-phosphate; AACT, acetoacetyl-CoA thiolase; HMGS, 3-hydroxy-3-methylglutaryl-CoA synthase; HMGR, HMG-CoA reductase; DMAPP, dimethylallyl diphosphate; IDI, isopentenyl diphosphate isomerase; IPP, isopentenyl pyrophosphate; FPS, farnesyl pyrophosphate synthase; GPP, geranyl diphosphate; FPP, farnesyl pyrophosphate; SQS, squalene synthase; SQE, squalene epoxidase; GA3P,glyceraldehyde-3-phosphate; DXP, 1-deoxy-D-xylulose-5-phosphate; DXS, DXP synthase; DXR, DXP reductoisomerase; DLR, DXR-like enzyme; HMBPP, 4-hydroxy-3-methyl-but-2-enylpyrophosphate; IspH,IPP/DMAPP synthase; SHC, squalene hopene cyclase. 
more favorable for squalene production. The maximum squalene production was noted to be $2.97 \pm 0.12$ and $3.13 \pm 0.11 \mathrm{mg} / \mathrm{L}$, whilst productivity of $\mathbf{0 . 1 0}$ and $\mathbf{0 . 1 6} \mathrm{mg} / \mathrm{L} / \mathrm{h}$ was gained for S. cerevisiae BY4741 and EGY48, respectively (Mantzouridou et al., 2009). Providing anaerobic condition is another proven strategy for enhanced production of squalene in T. delbrueckii (Bhattacharjee and Singhal, 2003). By providing a constant flow rate of $0.2 \mathrm{~L} / \mathrm{min}$ of carbon dioxide $\left(\mathrm{CO}_{2}\right)$, a temperature of $60^{\circ} \mathrm{C}$, and pressure of 250-255 bar, squalene yields up to $11.12 \mu \mathrm{g} / \mathrm{g}$ could be obtained using the supercritical fluid extraction (SFE) technique, an extraction method generally benefitting non-polar compounds and low molecular weight compounds (Bhattacharjee and Singhal, 2003). This yield could be further increased up to $430.52 \mu \mathrm{g} / \mathrm{g}$ by performing lyophilization (freezedrying) prior to SFE (Bhattacharjee and Singhal, 2003). In another study, a mutant strain of $S$. cerevisiae YUG37-ERG1 yielded about $18.0 \pm 4.18 \mathrm{mg} / \mathrm{L}$ of squalene when grown in grass juice (Lolium perenne) as feedstock with $0.025 \mu \mathrm{g} / \mathrm{ml}$ doxycycline (Hull et al., 2014). Other than S. cerevisiae strains, Kluyveromyces lactis could also be optimized for increased squalene production $\left(0.6 \mathrm{mg} / 10^{9}\right.$ cells $)$ by adding terbinafine $(7.5 \mathrm{mg} / \mathrm{L})$ as an inhibitor (Drozdíková et al., 2015).

A potential thraustochytrid Aurantiochytrium mangrovei FB3 strain acts as an alternative squalene producer in the fermentation industries through glucose concentration optimization. In an experiment, squalene content was lifted to $2.21 \mathrm{mg} / \mathrm{L}$ with a glucose concentration of $30 \mathrm{~g} / \mathrm{L}$. This yield was further elevated by 36 and $40 \%$ following treatment of 10 and $100 \mathrm{mg} / \mathrm{L}$ terbinafine, respectively, as compared to the control strain (Fan et al., 2010). Through optimization of culture conditions for the strain Aurantiochytrium sp. $18 \mathrm{~W}$ 13a, another group achieved $171 \mathrm{mg} / \mathrm{g}$ DCW squalene content (and $0.9 \mathrm{~g} / \mathrm{L}$ production) by utilizing $2 \%$ glucose and $50 \%$ seawater concentration in glucose-peptone-yeast medium (GPY medium) incubated at a temperature of $25^{\circ} \mathrm{C}$ (Nakazawa et al., 2012). Chen et al. (2010) screened various nitrogen sources and found that monosodium glutamate, yeast extract, and tryptone allow improved squalene production. Furthermore, optimal concentrations determined by a central composite experimental design anticipated to recover $6.61,6.13$, and $4.50 \mathrm{mg} / \mathrm{L}$ of squalene content and $6.94,6.22$, and $4.40 \mathrm{mg} / \mathrm{L}$ of squalene yield, respectively. The results were verified practically by achieving a squalene content of $0.72 \mathrm{mg} / \mathrm{g}$ and a squalene yield of 5.90 $\mathrm{mg} / \mathrm{L}$ for this strain. Likewise, Schizochytrium mangrovei was also studied for squalene production using 30 and $150 \mathrm{~L}$ bioreactors (Hoang et al., 2014). In the experiment, a squalene content of $33 \mathrm{mg} / \mathrm{g}$ DCW was recovered for both cases, while the yields reached 0.99 and $1.01 \mathrm{~g} / \mathrm{L}$, respectively (Hoang et al., 2014). Recently, this strain was analyzed for different fermentation conditions, wherein the maximum squalene content $(98.07 \mathrm{mg} / \mathrm{g}$ of lipid) was attained after $48 \mathrm{~h}$ of incubation in a $15 \mathrm{~L}$ medium containing 22\% glucose (Hoang et al., 2018). High squalene producing novel yeast-like fungus strain Pseudozyma SD301 has also been isolated. Highest titre of $2.44 \mathrm{~g} / \mathrm{L}$ squalene was achieved using fed-batch fermentation by providing glucose and yeast extracts to a ratio of 3, maintaining the system at $\mathrm{pH} 6$ and $25^{\circ} \mathrm{C}$, with supplementation of $15 \mathrm{~g} / \mathrm{L}$ of sea salt (Song et al., 2015).
Agricultural by-products are great economical and sustainable sources for fermentation and for the extraction of bio-compounds. Very recently, Fagundes et al. (2018) demonstrated an excellent finding by growing the cyanobacteria Phormidium autumnale in a bubble-column bioreactor with procured industrial slaughterhouse wastewater, accomplishing squalene amount totaling up to $0.18 \mathrm{mg} / \mathrm{g}$ DCW. Whilst the production they achieved was not otherwise sufficient industrially, they demonstrated a positive finding in this study by achieving squalene from waste and rubbish. The fermentation conditions and their optimization parameters are given in Table 3. Alteration or overproduction accomplished by genetic engineering of the microbes is discussed in the upcoming section.

\section{ENGINEERING OF MICROORGANISMS FOR SQUALENE PRODUCTION}

As microorganisms have rapid growth and insightful genetic background, they are easy to manipulate and use as a squalene microbial cell factories. In addition, quantum leap in molecular biology, synthetic biology, metabolic engineering and genome engineering have opened up new avenues for the production of numerous valuable chemicals, biofuels, and important metabolites from renewable sources (Rabinovitch-Deere et al., 2013; Singh et al., 2014, 2016; Chubukov et al., 2016; Gohil et al., 2017). By recognizing the minute aspects of the metabolic pathways and their flux, positive modifications around squalene producing pathways can be modulated to increase the synthesis of desired compounds.

\section{Engineering Saccharomyces cerevisiae for Squalene Production}

The accessibility and availability of wide range gene manipulating toolboxes allow easy manipulation of $S$. cerevisiae for industrial applications. In 1994, the first squalene accumulating S. cerevisiae was engineered through the disruption of a gene required for the conversion of squalene to ergosterol by homologous recombination in ergosterol biosynthesis pathway (EBP) of $S$. cerevisiae. As ergosterol is an integral constituent of the fungal plasma membrane, the generated mutants required this compound for faster growth. Accordingly, by feeding ergosterol into the system, squalene production could be increased up to $5 \mathrm{mg} / \mathrm{g}$ DCW under aerobic condition (Kamimura et al., 1994). In yeast, the ERG1 gene encodes a key enzyme of interest called squalene epoxidase, which is responsible for the conversion of squalene to squalene epoxide in the EBP. This ERG1 gene is a potent target of genetic manipulation toward increasing squalene production in yeast (Garaiová et al., 2014; Hull et al., 2014). Even point mutations in the ERG1 gene enable to achieve a higher amount of squalene yield (up to $1 \mathrm{mg} / 10^{9}$ cells) without any growth retardation (Garaiová et al., 2014). Thus, the resultant mutants could be hyper-sensitized to terbinafine, a squalene epoxidase inhibitor. Supporting this theory, Hull et al. (2014) developed a mutant strain S. cerevisiae YUG37-ERG1, which features a doxycycline-repressible tet $0_{7}-\mathrm{CYC1}$ promoter that regulates ERG1 gene expression, making the organism capable 
TABLE 3 | Fermentation optimization for squalene production.

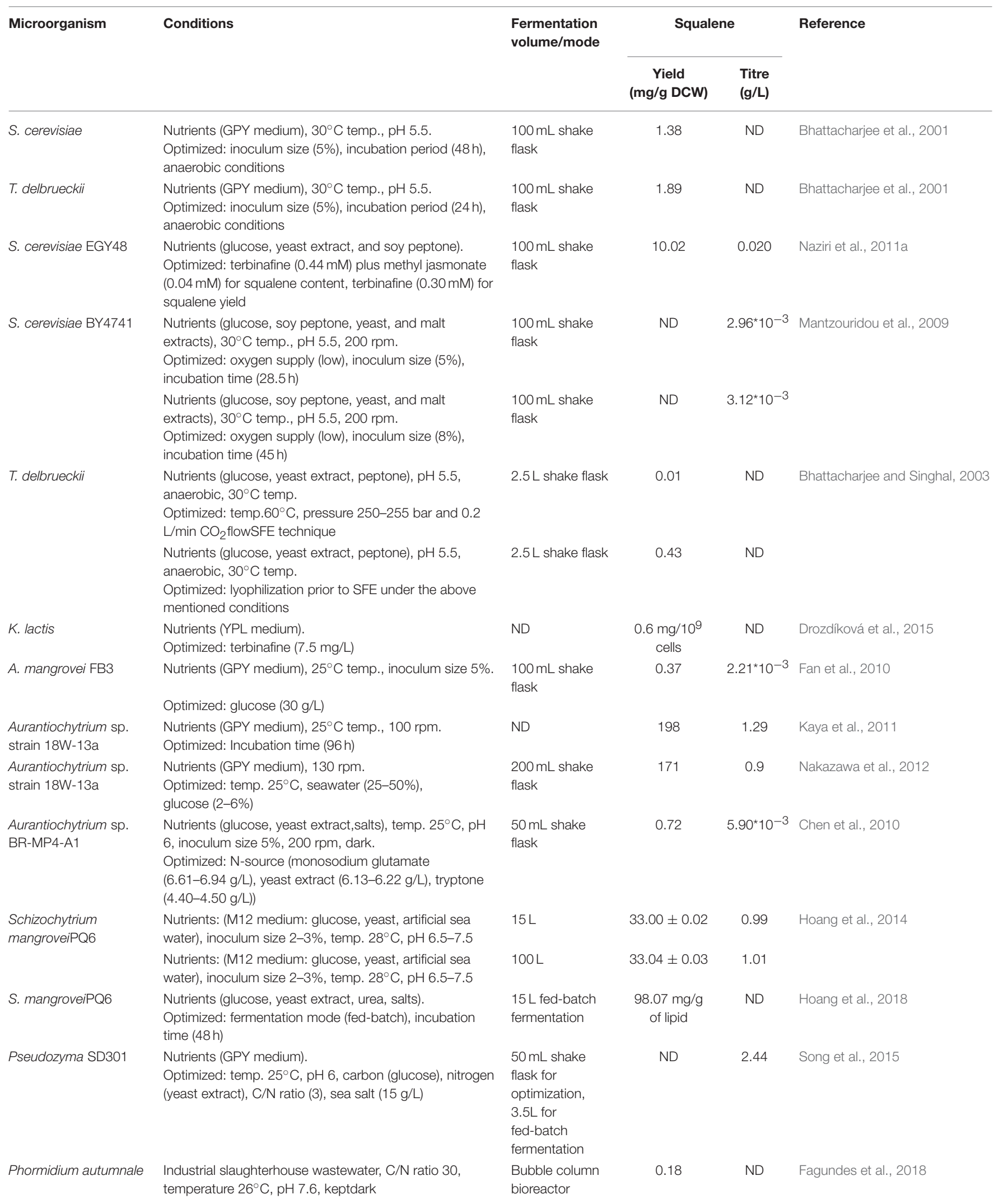

DCW, dry cell weight; ND, no data; temp, temperature; GPY, glucose peptone yeast; C/N, carbon/nitrogen; rpm, revolutions per minute; YPL, yeast peptone lactose; SFE, supercritical fluid extraction. 
of producing up to $7.85 \mathrm{mg} / \mathrm{g}$ squalene following addition of 50 $\mu \mathrm{g} / \mathrm{mL}$ doxycycline.

Another strategy for increasing the metabolic flux toward squalene in $S$. cerevisiae is to overexpress the genes which encode the rate-limiting enzymes (e.g., HMGR, ERG9) that are encountered in the MVA biosynthesis pathway. Yeast has two genes, HMG1 and HMG2, which encode HMGR. Overexpression of HMG1 gene has shown to overproduce squalene up to 191.9 mg/L (Tokuhiro et al., 2009). Similarly, Mantzouridou and Tsimidou (2010) investigated the effect of genetic perturbations in HMG2 and ERG6 (encodes sterol 24-C-methyltransferase that converts zymosterol to fecosterol) genes on squalene accumulation in S. cerevisiae EGY48. They constructed an AM63 mutant strain that harbors an additional copy of the HMG2 gene with a K6R stabilizing mutation in Hmg2p, an HMGR isoenzyme. Furthermore, they also created an AM64 strain by deletion of ERG6 gene from the AM63 strain. As a consequence, the AM63 mutant could produce squalene up to $18.3 \mathrm{mg} / \mathrm{g}$ DCW after $12 \mathrm{~h}$ of incubation that was 20 -fold higher than the control strain. Incidentally, the AM64 mutant could not accumulate squalene further, as it diverts surplus squalene into C27 sterols. Hmglp is another important NADPH dependent membrane-bound isomer of HMGR that contributes for more than $83 \%$ of enzyme activity in the wild-type strain (Basson et al., 1986; Paramasivan and Mutturi, 2017). By integrating double copies of truncated HMG1 (tHMG1) genes, squalene accumulation could be increased by 16.8 -fold in contrast to a single-copy of a gene in S. cerevisiae (Paramasivan and Mutturi, 2017). The tHMG1p enzyme requires NADPH cofactor, which is also an electron carrier in yeast, and accordingly the production could be further enhanced by 27.5 -fold $(28.4 \pm 1.08 \mathrm{mg} / \mathrm{L})$ through the co-expression of both $t H M G 1$ and POS5 (encodes an enzyme for NADPH regeneration) genes (Paramasivan and Mutturi, 2017). By implementing overexpression of the ERG9 gene along with insertion mutations in the ERG1 gene, $85 \mathrm{mg} / \mathrm{L}$ squalene has been produced in S. cerevisiae BY4741 (Zhuang and Chappell, 2015). Additionally, this has been further improved to $270 \mathrm{mg} / \mathrm{L}$ by expressing the truncated HMGR ( $t H M G R$ ) gene (Zhuang and Chappell, 2015). Similarly, Polakowski et al. (1998) overexpressed the HMGR by constructing and expressing the $t H M G 1$ gene under the control of a constitutive $A D H 1$ promoter. The resulting strain exhibited 2-fold increase in HMGR activity and 40-fold greater accumulation of squalene as compared to the parental strain S. cerevisiae AH22. Dai et al. (2014) performed similar experiments where they integrated tHMG1 with an addition of the LYS2 gene in S. cerevisiae BY4742-TRP, obtaining a significant amount of squalene $(150.9 \mathrm{mg} / \mathrm{L})$. Toward further increasing squalene accumulation, the $\beta$-amyrin synthase $(b A S)$ gene from Glycyrrhiza glabra was introduced with ERG9 and ERG1 genes. This emanated strain yielded $183.4 \mathrm{mg} / \mathrm{L}$ squalene. In addition, Kwak et al. (2017) co-expressed the tHMG1 and ERG10 (encodes Acetyl-CoA C-acetyltransferase) genes in $S$. cerevisiae SR7 (a xylose-utilizing engineered strain) and obtained up to $532 \mathrm{mg} / \mathrm{L}$ squalene within $54 \mathrm{~h}$ of incubation period in xylose fed-batch fermentation.

Overexpression of the entire squalene biosynthetic pathway in S. cerevisiae has also been demonstrated. Genes tHMG1, IDI1 (encodes isopentenyl-diphosphate-isomerase), ERG20 (FPS), and ERG9 were overexpressed under the control of HHF2p, IRA1p, PET9p, and RHO1p promoters, respectively, leading to an increased squalene production by 35.02 -fold $(119.08 \mathrm{mg} / \mathrm{L})$ when treated with terbinafine (Rasool et al., 2016a). Eventually, the complete biosynthetic pathway for squalene was overexpressed and that obtained a yield reaching as high as $304.49 \mathrm{mg} / \mathrm{L}$ (Rasool et al., 2016a). It was noted during the investigation that overexpression of the squalene biosynthetic pathway downregulates both ethanol production as well as post-squalene biosynthetic pathways (Rasool et al., 2016a).

An unexpected squalene accumulation (78 $\mathrm{mg} / \mathrm{L})$ was observed when Dai et al. (2012) inserted a gene to produce miltiradiene, a precursor of a well-known Chinese traditional medicine called tanshinone. Their attempt to overexpress tHMGR and upc2.1 (a mutated regulatory factor that induces sterol biosynthetic gene) in S. cerevisiae BY4742 to yield miltiradiene in upcoming steps surprisingly led to over accumulation of squalene as an intermediate product. Very recently, Han et al. (2018) overexpressed tHMG1 and ispA (bacterial FPP synthase) genes in S. cerevisiae Y2805 strain and obtained squalene concentration up to $400 \pm 45 \mathrm{mg} / \mathrm{L}$. They further increased squalene yield up to $756 \pm 36 \mathrm{mg} / \mathrm{L}$ by the inclusion of terbinafine for partial inhibition of SQE. Subsequently, they employed large-scale fed-batch fermentation and produced a yield of 2,011 \pm 75 and 1,026 $\pm 37 \mathrm{mg} / \mathrm{L}$ squalene with and without supplementation of terbinafine, respectively.

Strength of the promoter also plays a crucial role for balancing, tuning and optimizing the expression of a gene toward enhancing the metabolite concentrations. In this perspective, Rasool et al. (2016b) overexpressed the genes present in the squalene biosynthetic pathway with a newly characterized and optimized library of 13 new constitutive promoters in S. cerevisiae INVSc1. The resultant engineered strain FOH-0 produced up to $100 \mathrm{mg} / \mathrm{L}$ squalene that was 29.41 -fold higher than the control strain. They further improved squalene production in the FOH-2 strain by upregulating the entire squalene biosynthetic pathway, achieving $304.16 \mathrm{mg} / \mathrm{L}$ squalene in presence of terbinafine.

Wei et al. (2018) illustrated an approach for increasing the lipid content in yeast in order to increase squalene production. Accordingly, they overexpressed $t H M G 1$ and $D G A 1$, the latter being the gene that encodes diacylglycerol acyltransferase (a triacylglycerols biosynthesis enzyme), and deleted the PXA2 (a subunit of peroxisomal $\mathrm{ABC}$ transport complex involved in the transportation of long-chain fatty acids into peroxisomes) and POX1 (Fatty acyl-coA oxidase) genes to reduce lipid $\beta$-oxidation. The resultant strain boosted squalene accumulation by 250 -fold as compared to the control strain S. cerevisiae D452-2. However, it was noted that deletion of PXA2 and POX1 genes failed to give additional squalene enhancement, and did not help to accumulate the product of interest. In order to achieve a high titre, they performed fed-batch fermentation and obtained 445.6 $\mathrm{mg} / \mathrm{L}$ squalene from nitrogen restricted minimal medium.

All of the above studies show promising data for the improvement of squalene production toward the industrial applications. These engineered strains can be optimally grown in cheaper carbon and nitrogen from renewable and sustainable 
sources for the industrial scale production of squalene at more competitive prices than many alternatives.

\section{Engineering Escherichia coli for Squalene Production}

E. coli is a well-known model organism for the study of genetics, physiology, biochemistry, molecular biology, and many more. A reason why E. coli can be a lucrative source of squalene production is due to its inability to produce endogenous triterpenoids, owing to which the strains can stock up large amounts of biosynthesized squalene as they avert its conversion to undesired compounds. To facilitate this, single or multiple genes that pertain to squalene biosynthesis can be integrated into the MEP pathway.

An ample number of reports describe engineering of $E$. coli for the production of squalene through the extension of MEP biosynthetic pathway by inserting squalene synthase gene (SQS). In the first systematic study, three hopanoid genes including hopA, hopB (encodes squalene/phytoene synthases), and hopD (encodes farnesyl diphosphate synthase) from Streptomyces peucetius ATCC 27952 were successfully inserted and expressed in E. coli. The engineered E. coli was able to produce squalene up to $4.1 \mathrm{mg} / \mathrm{L}$ (Ghimire et al., 2009). There are number of rate limiting genes (e.g., idi, $d x s, d x r$ ) in the MEP pathway that could be overexpressed in order to improve squalene production. Inserting additional copies of $d x s$ and $i d i$ genes using plasmids for overexpression of rate limiting enzymes improved squalene production up to $11.8 \mathrm{mg} / \mathrm{L}$ (Figure 3A; Ghimire et al., 2009). In a similar study, Pan et al. (2015) introduced a three-step MEP extended squalene biosynthetic pathway in E. coli that included $h p n C, h p n D$, and $h p n E$ genes from Zymomonas mobilis and Rhodopseudomonas palustris. The pathway begins with enzyme hpnD catalyzing the conversion of two molecules of FPP to presqualene diphosphate (PSPP), followed by the PSPP being transformed into hydroxy-squalene (HSQ) and subsequently to squalene by enzymes hpnC and hpnE, respectively. This engineered strain could produce significant amounts of squalene (Figure 3B).

Insertion of a single squalene synthase gene (encoding $S Q S$ ) can also catalyze the conversion of two molecules of FPP (the end-product of the MEP pathway) into squalene (Figure 3C) (Furubayashi et al., 2014a; Katabami et al., 2015). It has been noted that SQS is NADPH dependent, a rate-limiting factor in cellular systems (Furubayashi et al., 2014a). This strategy also clearly requires codon-optimization. In a related study, the efficiency of two dissimilar codon-optimized SQS, namely human (hSQS) and Thermosynechococcus (tSQS) squalene synthases were analyzed in E. coli XL1-Blue strain. Between them, the $h S Q S$ expressed in the bacterial cells were found to produce squalene $(4.2 \mathrm{mg} / \mathrm{L})$. For further enhancement, the whole MVA pathway from S. cerevisiae was also introduced in E. coli for the very first time. Briefly, codon-optimized $t H M G R$, ERG13 (encodes hydroxymethylglutaryl-CoA synthase), ERG12 (mevalonate kinase), ERG8 (phosphomevalonate kinase), and MVD1 (mevalonate diphosphate decarboxylase) from $S$. cerevisiae were introduced along with the overexpression of $i d i$ and ispA (farnesyl diphosphate synthase). From this strain squalene content obtained was elevated up to 230 and $150 \mathrm{mg} / \mathrm{L}$ using $h S Q S$ and $t S Q S$, respectively (Figure 3D; Katabami et al., 2015). The study of the truncation effect on SQS revealed that the C-terminus retains partial cellular activity, sufficient to produce squalene (Katabami et al., 2015).

For indirect monitoring of squalene production, a CrtN based biosensor has been developed by transforming the $h S Q S$ gene along with the $\mathrm{CrtN}$ gene (dehydrosqualene desaturase) from Staphylococcus aureus. As a consequence, yellow colored pigmentation of the cells could be obtained because of the conversion of squalene into yellow carotenoid pigment (Furubayashi et al., 2014a). These results can also be used to assist the screening of cellular activity of different $S Q S$ genes (Furubayashi et al., 2014a).

Protein engineering is currently a powerful tool for improving enzyme activity, substrate specificity, and evolutionary fitness through the evolution of the enzymes of interest. Directed evolution of $S Q S$ genes was performed to determine the activity and evolutionary adaptability of the gene that could allow improved production of squalene (Furubayashi et al., 2014b). This study demonstrated that the direct evolution of different SQS genes from S. cerevisiae, humans, and Thermosynechococcus elongatus BP-1 could exhibit numerous beneficial mutations that could expand the activity of SQS (Furubayashi et al., 2014b).

As aforementioned, in S. cerevisiae, the immediate product after squalene is squalene epoxide which is the precursor of the paramountly important compound ergosterol that forms the basic unit of a fungal plasma membrane. Blocking or disrupting the pathway following squalene synthesis, owing to the accumulation of squalene leads to the death of the fungus (Jandrositz et al., 1991). Unlike S. cerevisiae, E. coli does not utilize squalene for further terpenoids conversion, making it a preferred choice of strain for many investigators. Additionally, the mindful targeting and downregulation of complementary pathways could also prove to be a suitable strategy to mitigate the resultant metabolic burden (Huang et al., 2018).

\section{Engineering Cyanobacteria, Algae, and Other Microorganisms for Squalene Production}

Genome sequencing of cyanobacteria Synechocystis sp. PCC 6803 (Kaneko and Tabata, 1997) revealed that it contains a complete set of genes that are required to produce hopanoids through the MEP pathway. In this pathway, squalene plays an important role as a precursor for hopanoids. Disabling shc gene (encodes squalene hopene cyclase which converts squalene to hopene) in Synechocystis could lead to accumulation of squalene $\left(0.67 \mathrm{mg} / \mathrm{L} / \mathrm{OD}_{750}\right)$ in the generated mutant strain without any detrimental effect upon cell growth (Englund et al., 2014). In another study, Choi et al. (2016) engineered cyanobacteria Synechococcus elongatus PCC 7942 to convert it into biosolarcell factories for production of squalene and amorpha-4,11diene from $\mathrm{CO}_{2}$, resulting in significant production of squalene $\left(4.98 \mathrm{mg} / \mathrm{L} / \mathrm{OD}_{730}\right)$. They overexpressed three important ratelimiting genes $(d x s$, idi, and $d x r$ ) of the MEP pathway along 


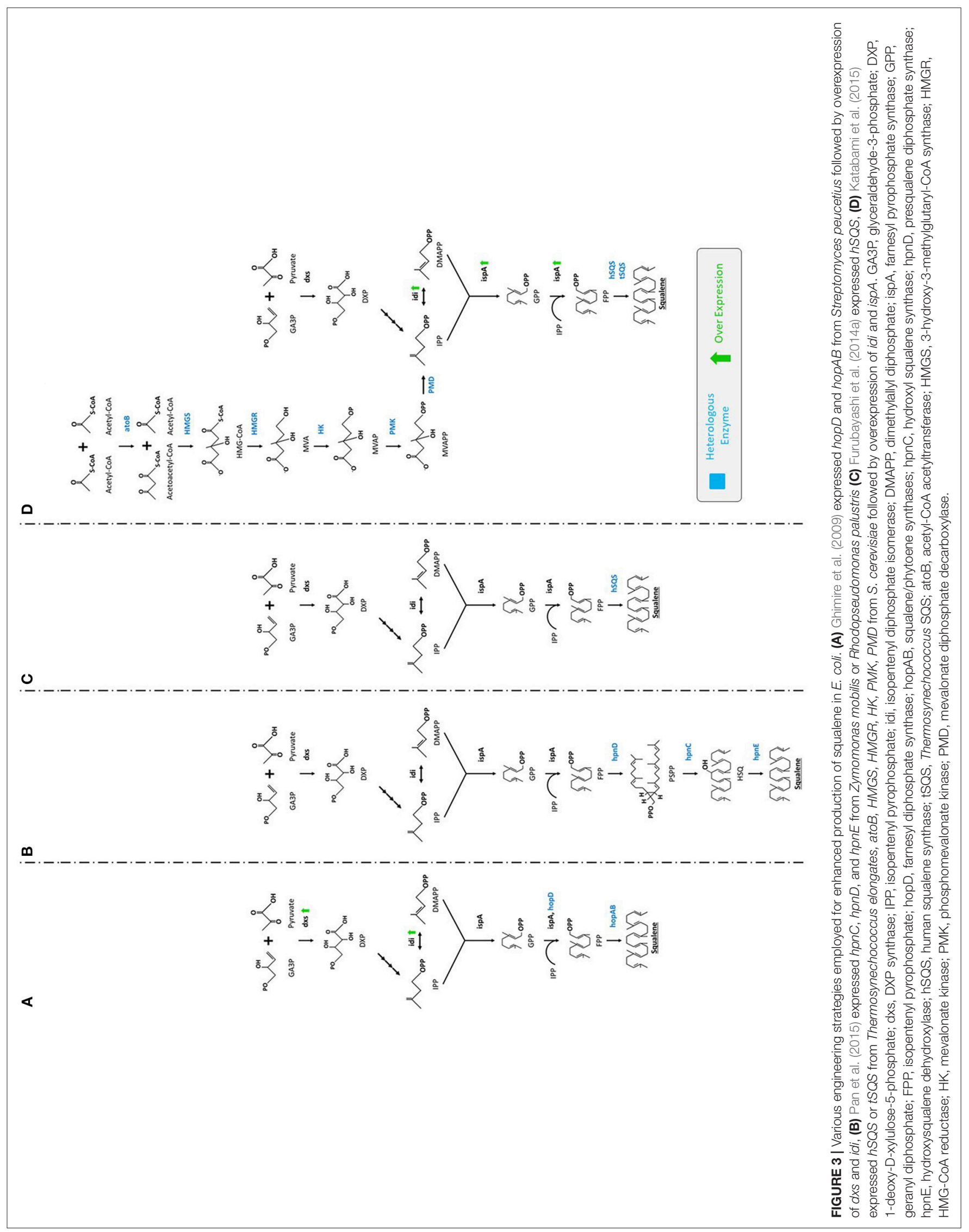


with the E. coli ispA gene in different combinations, finding that the mutant strain SeSC33S (dxs, idi, ispA overexpressed) was capable of producing a high amount of squalene (4.98 $\left.\pm 0.90 \mathrm{mg} / \mathrm{L} / \mathrm{OD}_{730}\right)$. A study looking at the fusion protein CpcB1-SQS found that its expression produced up to $7.16 \pm$ $0.05 \mathrm{mg} / \mathrm{L} \mathrm{OD}_{730}$ squalene (Choi et al., 2017). This output was further enhanced up to $11.98 \pm 0.49 \mathrm{mg} / \mathrm{L} / \mathrm{OD}_{730}$ through increasing the gene dosage (encoding CpcB1-SQS) using a strong endogenous $c p c B 1$ promoter (Choi et al., 2017). Moreover, a scalable yield was achieved $\left(7.08 \pm 0.5 \mathrm{mg} / \mathrm{L} / \mathrm{OD}_{730}, \sim 79.2 \mathrm{mg} / \mathrm{g}\right.$ DCW) by using a $6 \mathrm{~L} \mathrm{CO}_{2}$-fed bag-type photo-bioreactor with optimized conditions of $5 \% \mathrm{CO}_{2}$ under $100 \mu \mathrm{mol}$ photons $/ \mathrm{m}^{2} / \mathrm{s}$ (Choi et al., 2017).

Other than cyanobacteria, Xu et al. (2016) used the purple non-sulfur bacteria Rhodopseudomonas palustris TIE-1 for squalene production. They hypothesized and subsequently demonstrated that blocking shc gene (converts the squalene to the hopanoid) in the hopanoid pathway can aid accumulation of squalene in this strain. Investigators could enhance squalene production by 27 -fold $(3.8 \mathrm{mg} / \mathrm{g}$ DCW $)$ as compared to the control strain. They could further improve the production of squalene up to $9.9 \mathrm{mg} / \mathrm{g}$ DCW by increasing carbon-flux toward FPP (the precursor of squalene) via co-expression of genes $\mathrm{crtE}$ and $h p n D$. Interestingly, when they fused the proteins CrtE and $\mathrm{HpnD}$ by a linker molecule (GGGGS) 3 , squalene content increased up to $12.6 \mathrm{mg} / \mathrm{g}$ DCW. Finally, they overexpressed the rate-limiting enzyme DXP synthase (encoded by $d x s$ ) of the MEP pathway and produced $15.8 \mathrm{mg} / \mathrm{g}$ DCW that drove a 112 -fold increase as compared to the wild-type strain.

Increasing the squalene precursor pool size is also an attractive strategy. As an alternative strategy, oleaginous yeast Yarrowia lipolytica was engineered in a way that it would supply the requisite amount of precursors to itself for improving squalene yield (Huang et al., 2018). The metabolite pool size of acetyl-CoA (the start point of the MVA pathway) was increased by overexpressing the codon-optimized heterogeneous acs gene (encoding acetyl-CoA synthase) from Salmonella enterica, and coupling this with the endogenous ylACL1 gene (ATP citrate lyase) resulted in a 50\% acetyl-CoA enhancement. When this desired acetyl-CoA rich MVA pathway was boosted by overexpressing $y l H M G 1$ gene, $3.3 \mathrm{mg} / \mathrm{g}$ DCW squalene was produced. The level of squalene was enhanced up to 7 and $10 \mathrm{mg} / \mathrm{g}$ following supplementation of $20 \mathrm{mM}$ sodium acetate and $10 \mathrm{mM}$ citrate, respectively (Huang et al., 2018).

In addition to this, Kajikawa et al. (2015) exploited the transgenic Chlamydomonas reinhardtii to investigate the squalene accumulation capacity of the microalgae by characterizing microalgal squalene synthase (CrSQS) and squalene epoxidase (CrSQE). Overexpression of the CrSQS illustrated that CrSQS increases the rate of conversion of FPP to squalene. However, it failed to accumulate more squalene content. Furthermore, they noted that knocking down of CrSQE, resulted in squalene accumulation being enhanced by up to $1.1 \mathrm{mg} / \mathrm{g}$ DCW. Thus, it was suggested that the partial suppression of CrSQE is an effective strategy for squalene accumulation in C. reinhardtii. The various engineering strategies along with their achieved squalene outputs are given in Table 4 .
The future holds great possibilities to attempt engineering microbes, as there remain many unexplored strains to date that may show improved options for the synthesis of the desired product. However, this may bring along several unintended risk factors such as chances of interbreeding, impact on the ecosystem, enhanced selection pressure on organisms and/or horizontal transfer of recombinant genes to other microbes during conjugation (Prakash et al., 2011). A probable way to avoid such ascertainable risks is by following the International biosafety regulatory frameworks (Prakash et al., 2011).

\section{POTENTIAL APPLICATIONS OF SQUALENE}

Squalene has been used for a wide range of applications and has huge impacts on our daily life. It has the ability to serve as a powerful antioxidant, anti-cancer agent, vehicle to transport drugs and vaccines, and its role in skincare and personal care products undoubtedly underscores the beneficial effects of squalene. The Japanese have been designating squalene as "Tokubetsu no Miyage" meaning "a precious gift," acknowledging it as a source of strength, power, and vitality. Locals of the Izu peninsula of Japan have been using squalene to treat numerous diseases and conditions, owing to which they designated squalene as "Samedawa," meaning "cure-all" (Popa et al., 2015). The inherent applications of squalene in nutraceutical, pharmaceutical, a drug carrier, detoxifier etc. are shown in Figure 4.

\section{Squalene as an Anticancer Agent}

Cancer is one of the most dreadful diseases that mankind faces, and it generally manifests as uncontrolled growth of cells that can metastasize into other parts of the body. A wide range of studies have shown that the regular consumption of squalene may inhibit the proliferation of tumor cells, especially those of the breast, pancreas, colon, and melanoma, the activation of which depends on the prenylation of proteins (Newmark, 1997; Cirmena et al., 2018).

Many oncogenes are involved in cancer initiation and progression, amongst which the Ras oncogene plays a leading role in initiating cancer by transforming healthy cells into malignant one (Fernández-Medarde and Santos, 2011). Under the physiological conditions, the Ras gene functions as a switch that regulates the cell growth, but in tumor cells, the hyperactivated Ras gene promotes the autonomous growth of cells. Ras proteins are required to undergo isoprenylation during their activation and anchorage to the cell membrane (Fernández-Medarde and Santos, 2011). During the cell division when the cells transit from the G1 phase to $S$ phase, some vital isoprenylated proteins translocate to the cell membrane as well as to the nuclear envelope. The isoprenylation of these proteins is facilitated by GPP and FPP, which in turn are regulated by squalene. Dysregulated isoprenylation of certain proteins affects the Ras signal transduction process in actively proliferating and differentiating cells. Therefore, it proves to be calamitous, especially for the Ras hyperactivated tumor cells, 
TABLE 4 | Squalene production in engineered microorganisms.

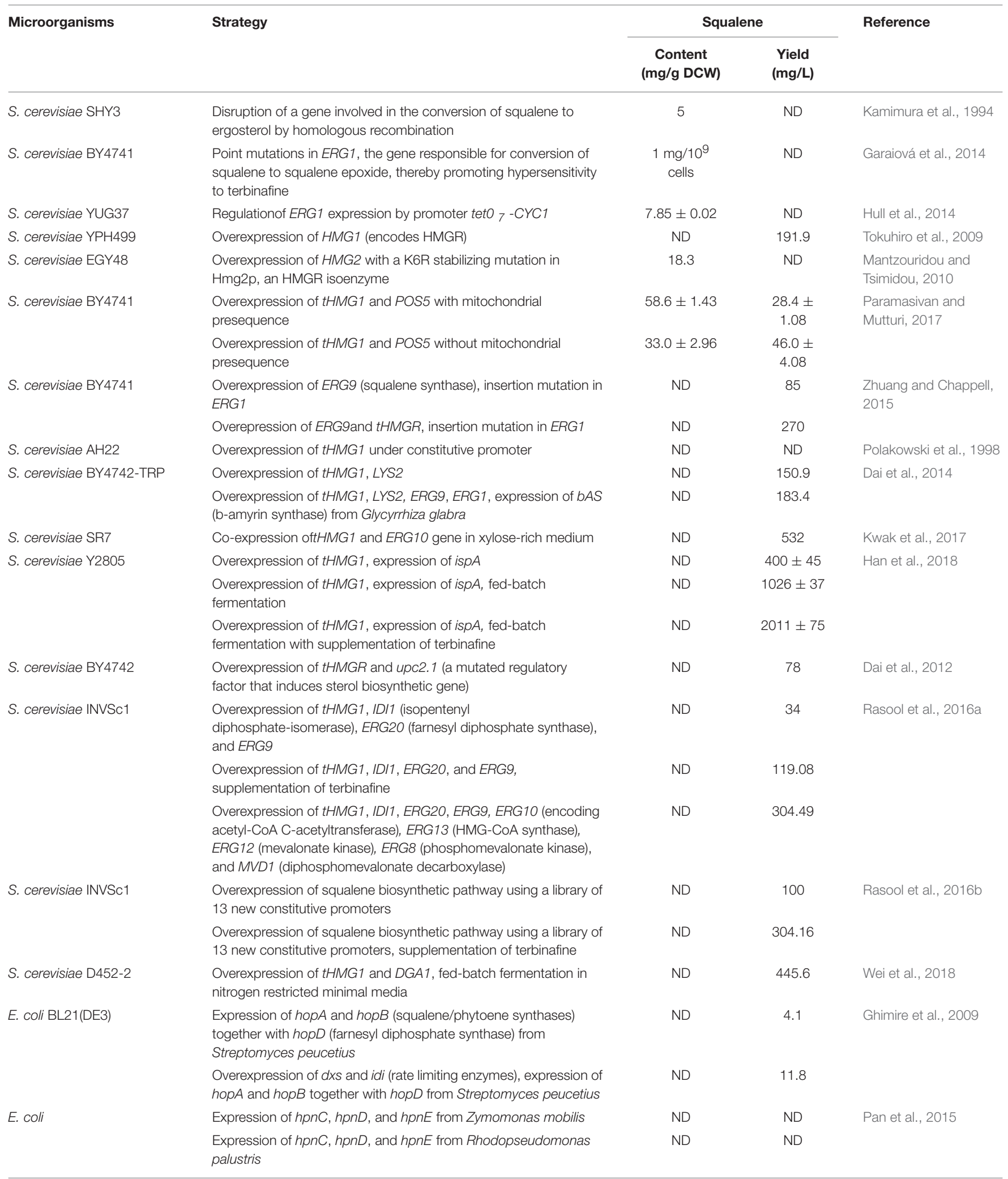


TABLE 4 | Continued

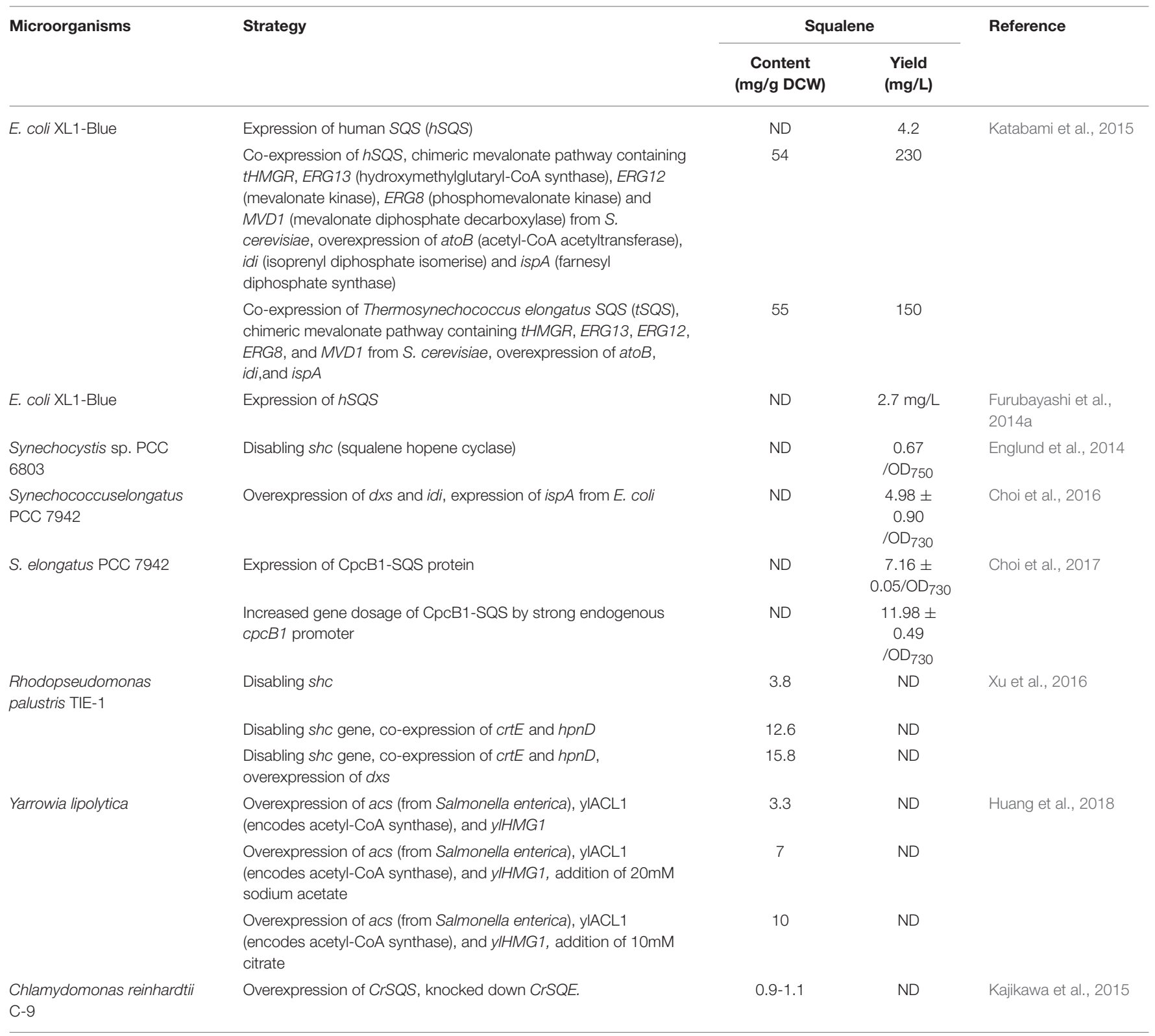

HMGR, HMG-CoA reductase; tHMG1, truncated HMG1; tHMGR, truncated Hydroxymethylglutaryl-CoA reductase.

as well as the normal cells (Rao et al., 1998; Smith, 2000). A dietary intervention of squalene inhibits isoprenoid production by setting up a negative feedback in response to the presence of exogenous squalene (Ronco and De Stéfani, 2013). The inhibition takes place because down-regulation of HMGR decreases the synthesis of FPP, thus suspending the MVA pathway and thereby inhibiting the isoprenylation of Ras proteins. By arresting the cells at the G1 phase of the cell cycle, squalene prevents the proliferation of cancer cells.

In several reports, cancer has been linked with the feeding style of the population in question. A diet rich in squalene, antioxidants, and fiber has been associated with a decline in the mortality rate amongst the populations that consume a high amount of olive oil. Particularly, the Mediterranean diet that includes a fair share of squalene and phenolic compounds from the consumption of fish and olive oil lowers the incidence of degenerative diseases (Newmark, 1997; Owen et al., 2004). According to Smith (2000), squalene restricts carcinogenesis by three identified mechanisms. Firstly, it inhibits the action of HMGR and prevents the conversion of HMG-CoA into MVA. Secondly, it tightly regulates the metabolism of xenobiotic compounds by modulating the biosynthesis of the enzymes that are involved in the process. Thirdly, squalene can scavenge the free radicals and singlet reactive oxygen that are responsible for causing a mutagenic lesion in the DNA, ultimately leading to cancer. 


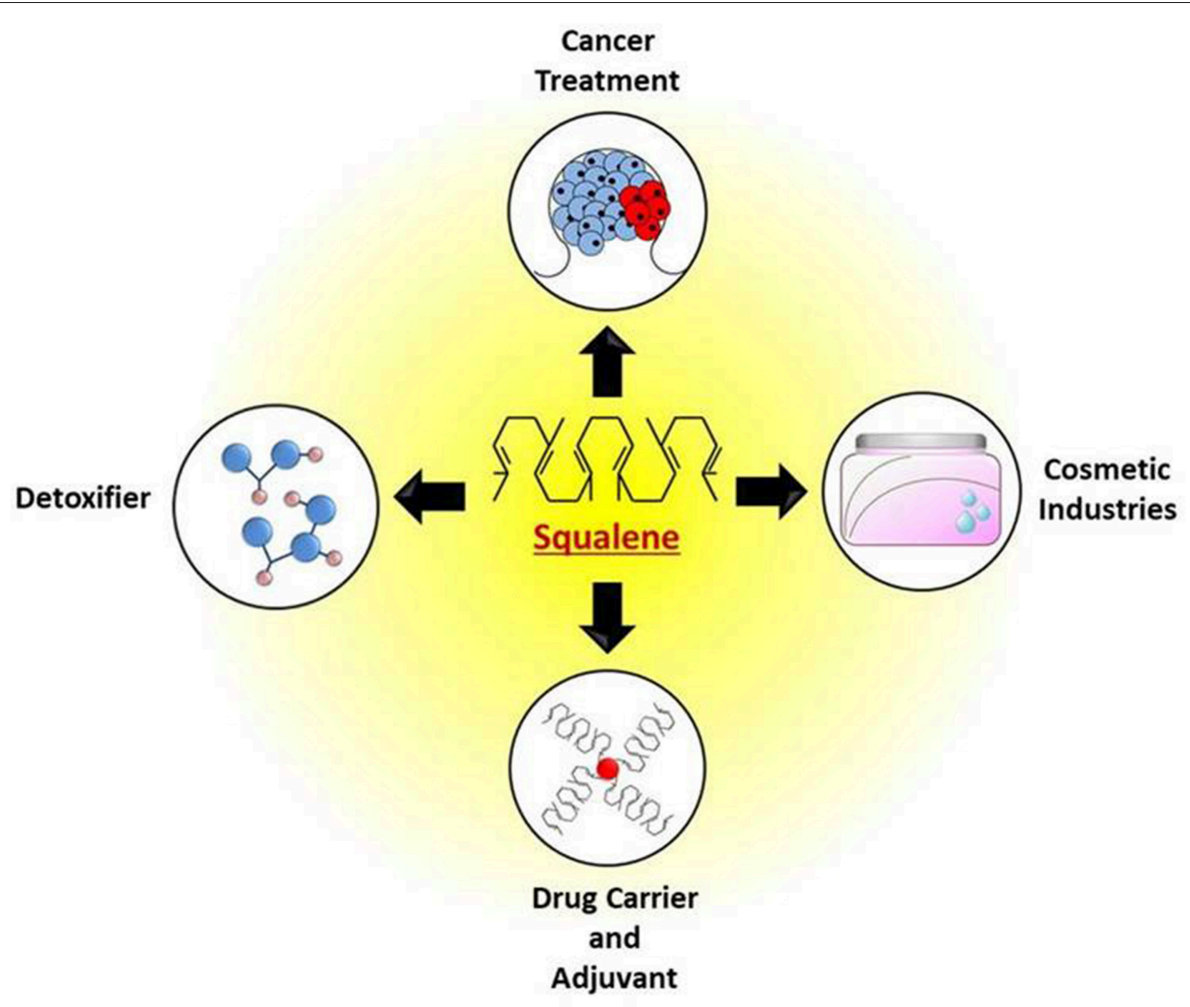

FIGURE 4 | Potential applications of squalene for treatment of cancer, as detoxifier, use in cosmetics, drug and vaccine adjuvants.

Early reports have suggested that a combination therapy of anti-cancer drugs emulsified with squalene have shown to intensify the efficacy of drugs both directly and indirectly (Yarkoni and Rapp, 1979). Moreover, the increase in the beneficial cytotoxic effect of potent drugs such as adriamycin, 5 -fluorouracil, bleomycin, and cisplatin on administration with squalene has already been reported (Nakagawa et al., 1985). The response of certain drugs, when co-administered with squalene, can greatly differ between breast cancer cells and normal mammary epithelial cells. Warleta et al. (2010) studied the effect of squalene on cell proliferation, apoptosis, oxidative stress, and cellular damage resulting from reactive oxygen species (ROS) in human breast cells. From their findings, they deduced that squalene reduced the levels of intracellular ROS and oxidative damage, generated in vitro by $\mathrm{H}_{2} \mathrm{O}_{2}$, in normal epithelial cells but not in breast tumor cells.

Similarly, it was demonstrated that squalene has the ability to selectively protect the normal cells against the cytotoxic effect of the anti-cancer drugs, but it does not extend the same protective mechanism to tumor cells (Das et al., 2003). In the subsequent study, Das et al. (2008) presented the experimental evidence of squalene's role in protecting healthy bone marrow cells while having no obvious effect on the neuroblastoma cells. A related study in rats that were each fed $0.4 \mathrm{~mL} /$ day of squalene signified the protective role of this triterpene on cyclophosphamideinduced toxicity in the kidney, liver, and heart of the rats (Senthilkumar et al., 2006a,b).
Rapid DNA synthesis is a hallmark of cancer. To design anticancer therapeutics that target the process, pro-drug strategies dealing with quick and efficient transportation of nucleotide analogs have been employed (Couvreur et al., 2006). Originally designed to be a powerful anti-viral tool, these nucleotide analogs are significantly different from their nucleotide counterparts and can inhibit DNA synthesis in rapidly dividing cells (Couvreur et al., 2006). However, the permeability of these nucleotide analogs is restricted due to their hydrophobicity and unfavorable pharmacodynamics. Squalenylation is the process of coating anticancer or antiviral drugs with squalene to increase the permeability and cytotoxic activity, and it helps in overcoming the described limitations by greatly increasing the intracellular accessibility of these compounds (Couvreur et al., 2006). An example of this is the enhanced membrane permeability and interaction of the gemcitabin-squalene complex as compared to free gemcitabin (Castelli et al., 2007; Pili et al., 2010; Peramo et al., 2018).

\section{Squalene as an Antioxidant}

Squalene has long been recognized as a potential antioxidant candidate. It has the capacity to entrap thermodynamically active singlet oxygen atoms that are generated from autohydrolytic reactions and resultant oxidative products (Pham et al., 2015). The chemical structure of squalene shares close resemblance with lycopene ( $\beta$-carotene), the carotenoid pigment responsible for red color of many fruits and vegetables, as well as 
some endogenous antioxidants including glutathione, superoxide dismutase, ubiquinone (coenzyme Q10), and vitamins A, E, and $\mathrm{K} 1$, all of which are notable antioxidants (Huang et al., 2009; Ronco and De Stéfani, 2013). The six unconjugated double bonds of squalene make it a highly sustainable oxygen-scavenging agent that is more stable against oxidation arising from peroxides.

Prolonged exposure to sunlight or ultra-violet (UV) radiation by any means gives rise to highly reactive free radicals in the system, leading to biomembrane destruction, premature skin aging, and other associated diseases (Kohno et al., 1995). Moreover, the human skin is not as hairy as other primates and therefore is prone to undergo rapid peroxidation of endogenous lipids through exposure. In the skin, squalene may act as a powerful quencher of singlet oxygen, thereby preventing the lipid peroxidation (Kohno et al., 1995; Kelly, 1999). Data from the photoluminescence studies of squalene using mass spectrometry revealed that it is the double bonds of the squalene that binds with oxygen and prevent photooxidation by UV rays (Mudiyanselage et al., 2003). Squalene has the prodigious ability to take up a greater amount of free oxygen as compared to any other lipid present in the human skin (Kohno et al., 1995). It has the ability to take up about one-fourth of its weight of oxygen, allowing squalene to prevent the development of wrinkles, acne, and comedones (Huang et al., 2009).

A number of studies support the fact that three major phenolic constituents of olive oil (simple phenols like hydroxytyrosol and tyrosol, secoiridoids, and lignans) along with squalene, vitamin $\mathrm{E}$, and monounsaturated fatty acid (oleic acid) offer protection against many cancers and coronary heart diseases (Owen et al., 2000a,b). Intake of $>13.5 \mathrm{~g} /$ day of squalene is proven to reduce the facial wrinkling, enhance the type I procollagen expression, and decrease the facial erythema along with substantially reducing the risk of UV-induced damage to the DNA (Murakoshi et al., 1992; Cho et al., 2009).

The metabolism of a number of anticancer drugs often releases highly toxic free radicals. Cyclophosphamide, also known as cytophosphane, and chloroacetaldehyde, are metabolized in the kidney. The nascent oxygen released from their metabolism generates oxidative stress in the kidney leading to its early damage (Rehman et al., 2012). Adriamycin (Doxorubicin) is known to form superoxide anions that are pernicious to cardiac tissues (Rahman et al., 2007). Apart from these, the anticancer drugs that bear platinum can affect bone marrow over longterm use. Squalene may help to neutralize the adverse effect of these drugs by absorbing the free radicals and pacifying the oxidative stress.

\section{Squalene in the Skin and Personnel Care}

Considered amongst the best-known emollients, squalene is one of the common components of the human sebum and the compatibility it shares with lipids present in the skin explains its extensive use in the cosmetic industries. Squalene, together with its hydrogenated analog squalane, has the ability to occlude moisture in the dermal layers, thus counteracting the appearance of fine lines and dry patches. It penetrates into deeper layers of skin and provides elasticity, restores suppleness, and drastically improves the flexibility. Moreover, though technically a lipid, squalene leaves little oily residues and is safe to use on sensitive and acne-prone skin (Sethi et al., 2016).

The ability of squalene to serve as a quencher of singlet oxygen and sustain lipid photo-peroxidation explains its role in the formulations of anti-aging creams and sunscreens. Using harsh skin cleansers, not only eliminate the dirt but also rob moisture from the skin. Squalene has been found to reverse the elevated transepidermal water loss (TEWL) along with riboflavin penetration in sodium lauryl sulfate (SLS)-treated rats and human skin (Okuda et al., 2002). Besides being an excellent hydrating agent, topical applications of squalene-based products are used to treat skin disorders including acne, psoriasis, xerosisrelated skin lesions, seborrheic dermatitis, and atopic dermatitis (Wołosik et al., 2013; Hon et al., 2018). An in vivo study on the delivery of psoralen, an anti-psoriatic medicine, suggests that entrapment of the drug inside a nanostructured lipid carrier based on squalene and precirol facilitates better skin permeability and controlled release of the drug (Fang et al., 2008).

Rissmann et al. (2008) developed a semi-synthetic lipid formulation that could mimic the composition, organization, and thermotropic behavior of vernix caseosa (VC) lipids, presuming their role in acting as a protective barrier, as it does for the human fetus. A set of mixtures were generated by mixing varying lipid fractions isolated from lanolin with squalene, triglycerides, cholesterol, ceramides, and fatty acids which resulted in improved barrier recovery in barrier-deficient skin (i.e., for psoriasis). Other than the applications of squalene in emollients and moisturizers, squalene can aid the quick dispersion of the dyes from lipsticks, resulting in a glossy finish and potentially prolonging the long-lasting fragrances by fixing the perfumes. Squalene when applied over the damaged or washed hair and skin can readily form an emulsion with the oils or other lipophilic substances. It may prevent them from turning rancid, thereby helping to restore the natural oil (Wołosik et al., 2013). Given the properties of squalene as a natural emollient and moisturizer, the scope for squalene to find more application in the cosmetic sector is widespread and immense.

\section{Squalene as a Drug and Vaccine Carrier}

Squalene has been used for the formulation of drug delivery and as a vaccine adjuvant candidate. Owing to its lipophilicity and excellent surface tension, squalene has been extensively used for preparing the stable oil-in-water emulsions for the purpose of delivering active hydrophobic compounds. The slow release of these active compounds enhances the biodistribution and aids improved uptake by the cells (Naziri et al., 2011b). Moreover, reports suggest that the ease with which a lipid carrier interacts with endogenous body fluid and tissues readily decreases the possibility of adverse effects (Nicolaos et al., 2003; Huang et al., 2009). Squalene emulsions possess a high degree of transfection activity and are known to delineate very low systemic toxicity following intravenous administration in vivo (Kim et al., 2003). Additionally, squalene in comparison to other lipids can form fairly stable emulsions that facilitate the delivery of a lipophilic drug when loaded into the discontinuous oil phase (Chung et al., 2001). 
Squalene prepared into emulsion either as the lone ingredient or in combination with other components can readily improve the functioning of a drug and may also help to elicit a favorable immune response against the exogenous antigen (Kedl and Kedl, 2015). A lecithin-squalene emulsion in conjugation with Tween 80 (polysorbate 80 ) has been found to be effective in stimulating the antibody production, while squalene emulsion alone was found to assist the efficacy for an influenza vaccine (10 mg squalene/dose) (WHO, 2006; Kim and Karadeniz, 2012). In a recent study, a group of researchers developed a squalenecontaining solid lipid nanoparticle formulation. This formulation was designed keeping yeast vaccines in mind and comes with added advantages of steam sterilization and the fact that it can be freeze-dried and stored in a powdered form coupled with the vaccine. The designed complex could successfully produce immune stimulating effects that were comparable to Freund's adjuvant and the commercially available squalene nanoemulsion AddaVax $^{\text {TM }}$ (Stelzner et al., 2018).

In vivo studies on rat models have helped to generate substantial evidence supporting the use of squalene emulsions with phosphatidylethanolamine or Pluronic ${ }^{\circledR}$ F68 for improved parenteral drug delivery of morphine and its prodrugs. The slow release of drug prolongs the analgesic effect in the preclinical model. The antinociceptive activity analyzed through the cold ethanol tail-flick test revealed that as compared to the aqueous formulations, the lipid-based emulsions exhibit an extended analgesic response (Wang et al., 2008).

Several controversies have revolved around the use of squalene as an adjuvant for the anthrax vaccine (Asa et al., 2000). A downside of using squalene was debated following its relation to treatments of Gulf War Syndrome (GWS) that included a pool of symptoms such as fatigue, headache, diarrhea, rashes and allergies, memory loss and neurological abnormalities, arthralgias, myalgias, and lymphadenopathy (Gronseth, 2005; Lippi et al., 2010). The unexpected finding of the anti-squalene antibodies in patients with GWS spiked speculation about its safety and its adverse effects (Asa et al., 2002). However, these are now regarded as uncorroborated findings given the fact that humans naturally possess anti-squalene antibodies and therefore the presence of the mentioned antibodies may not contribute to, or indicate the development of GWS (Matyas et al., 2004). This conjecture was further strengthened with the approval of a squalene-based MF59 emulsion adjuvant that neither raised the anti-squalene antibody levels nor modified the pre-existing titres (Del Giudice et al., 2006).

MF59 is potent oil in water-based emulsion designed by Novartis ${ }^{\circledR}$, with about $4.3 \%$ squalene present in the dispersed phase, and surfactants including Span85, Tween 80, and citrate constituting the continuous phase. The emulsion has worked well for several vaccines including malaria (Patra et al., 2015), herpes virus (Hensel et al., 2017), hepatitis B and C viruses (Del Giudice et al., 2006), H1N1 flu (Lippi et al., 2010), and HIV (Del Giudice et al., 2006). Although the exact biological mechanism is not yet clear, it is predicted that MF59 elicits an immune response by recruiting the phagocytic cells to the site of delivery, promoting maturation of monocytes into dendritic cells, and facilitating their transport to nearby lymph nodes to trigger the adaptive immune response (Seubert et al., 2008; Sánchez-Quesada et al., 2018). In the near future, more research needs to be done for achieving the full potential of squalene as a carrier in drug and vaccine for controlling of many serious diseases.

\section{Squalene as a Detoxifier}

Human body tends to accumulate a large amount of xenobiotics (i.e., man-made complex chemicals not found in nature) that are hazardous and can have detrimental effects on health. These compounds interfere with the normal physiological functioning by either acting as potential pro-carcinogens or by mimicking the receptor structure of sex hormones (Omiecinski et al., 2011; Mackowiak and Wang, 2016). Some are inherently nontoxic but turn hazardous following biotransformation by the hepatic cytochrome P450 enzymes (Ioannides et al., 2004). These chemical compounds are usually lipophilic in nature and they are compelled to be drawn toward fat. Squalene being nonpolar in nature has a high affinity for such unionized compounds and therefore facilitates the removal of xenobiotic compounds from the body (Kelly, 1999).

In an attempt to clear the xenobiotic compounds, liver breaks down the noxious products into smaller ones. Squalene stored in the fat cells can act as a detoxifying agent by clearing these compounds. The accumulation of xenobiotics in the fat cells frees the squalene conserved within the cells, which gets released into the circulation. This, in turn, accelerates clearance by stimulating bile secretion (Günes, 2013). A diet supplemented with $8 \%$ of squalene has been found to improve the faecal elimination of organochlorine xenobiotics including hexachlorobiphenyl (6-CB) and hexachlorobenzene (HCB) (Richter and Schäfer, 1982; Richter et al., 1982). A few other toxins such as dibenzofurans, 12-O-Tetradecanoylphorbol13-acetate (TPA) and 4-(Methylnitrosamino)-1-(3-pyridyl)-1butanone (NNK) (Murakoshi et al., 1992) are also known to be detoxified by squalene. Animal studies reveal that squalene also enhances the removal of xenobiotics such as theophylline, strychnine, and phenobarbital (Kamimura et al., 1992; Kelly, 1999). Hence, it can be presumed that the detoxification power of squalene is a function of its ability to purify and clean the biological systems.

\section{CONCLUDING REMARKS AND PERSPECTIVES}

Squalene shows an impressive range of human applications to date, ranging from a protective anti-cancer (Kim and Karadeniz, 2012; Günes, 2013) and anti-oxidant (Amarowicz, 2009; Günes, 2013) compound to one that assists cosmetics, pharmaceutical drugs, and vaccines and drug delivery (Del Giudice et al., 2006; Pasquale et al., 2015), augmenting their potency and selectivity. Acknowledging its wide range of uses, squalene has been called "Tokubetsu no Miyage" or "a precious gift" in Japanese, and it is clear why. Due to its biological properties and uses in numerous commercial formulations, its synthesis and recovery show great global demand that is reflected in 
its high market value (Global Market Insights, 2016; RosalesGarcia et al., 2017a). This continues to grow and is projected to advance further with time, especially if novel applications of squalene are discovered. Clearly with the potency of squalene in so many varied formulations, it would likely find use in new formulations that would demonstrate similar benefits, and the future of squalene is full of novel applications awaiting discovery.

While living up to its Japanese name as a biologically precious gift, the biggest immediate hurdle in expanding the growth of squalene supplies and markets are its primary sources, and specifically their link with the decimation of shark populations (Ciriminna et al., 2014; Tsoi et al., 2016). Given the ethical and social concerns around this topic, the likelihood that sharks should, or even could, remain the primary source of squalene is doubtful (Dulvy et al., 2008). On weighing the benefit of squalene against bioconservation and protection of sharks, we feel that this should compose an overly great challenge, as modern science has advanced to a position where mankind can subvert biological systems genetically, and thereby improve and exploit existing strains that do not suffer bioconservation or ethical use problems. Squalene is produced from only two pathways biologically, the MEP and MVA pathways (Spanova and Daum, 2011; Popa et al., 2015; Rani et al., 2018). Within the pathways and their contexts, biologists and biochemists have modified, truncated, duplicated, deleted, and improved numerous targets, showing positive increase in squalene accumulation. Likewise, naturally producing species (excluding sharks) have been examined, ranging between microbes, plants, and fungi, demonstrating a wide choice of alternative target organisms for the synthesis and accumulation of this compound.

Currently, the amounts of squalene recovered from any alternative source are pale in comparison to sharks, but the potential for further improvement in these species and their fermentation remains interesting, and perhaps more importantly, plausible. Interesting findings in this context include the oleaginous yeast Pseudozyma sp. JCC 207, which provides considerable yields of squalene (Chang et al., 2008) that approach commercially viable levels. Likewise, the fungus $T$. delbrueckii has also been shown to synthesize commercially relevant amounts of squalene from fermentation and the SFE technique (Bhattacharjee et al., 2001; Bhattacharjee and Singhal, 2003). Alternatively, the discovery of cheaper and more renewable sources can reduce the barrier to entry for alternative squalene sources, such as cyanobacteria $P$. autumnale, which could use

\section{REFERENCES}

Aasen, I. M., Ertesvåg, H., Heggeset, T. M. B., Liu, B., Brautaset, T., Vadstein, O., et al. (2016). Thraustochytrids as production organisms for docosahexaenoic acid (DHA), squalene, and carotenoids. Appl. Microbiol. Biotechnol. 100, 4309-4321. doi: 10.1007/s00253-016-7498-4

Aioi, A., Shimizu, T., and Kuriyama, K. (1995). Effect of squalene on superoxide anion generation induced by a skin irritant, lauroylsarcosine. Int. J. Pharm. 113, 159-164. doi: 10.1016/0378-5173(94)00190-G

Amarowicz, R. (2009). Squalene: a natural antioxidant? Eur. J. Lipid Sci. Technol. 111, 411-412. doi: 10.1002/ejlt.200900102 literal waste and rubbish as a source to generate low amounts of squalene (Fagundes et al., 2018).

In the majority of cases examined, the use of fermentation increased the yields and titres of squalene, and this could be improved through various optimization practices and the use of specific inhibitors, such as terbinafine. With the recent and rapid growth in synthetic biology, the ability to modify the MEP/MVA pathway as well as other competing pathways around squalene could be a means to attain improved squalene biosynthesis. The primary concern will drive the microorganisms and the alternative species of choice toward higher yields and titres, something that will likely come through the incremental steps of improvement that will ultimately, and hopefully, reach commercially viable levels. The discovery of new species that may have more malleable biosynthesis pathways or higher native squalene content could also be a priority, as in any case the major and primary source of this incredible compound is not sustainable, both ecologically as well as commercially. Having reviewed the incredible range of applications of squalene, and the exciting work and accomplishments to increase its yield from sustainable biological sources, the description of squalene as an ultimate "precious gift" seems more and more achievable.

\section{DATA AVAILABILITY}

All datasets generated for this study are included in the manuscript and/or the supplementary files.

\section{AUTHOR CONTRIBUTIONS}

NG, GB, KK, DB, and VS have designed and written the manuscript. VS has supervised and finalized the final version of the manuscript.

\section{ACKNOWLEDGMENTS}

This work was supported by The Puri Foundation for Education in India. The authors thank to all members of the lab for their discussion and comments. The authors also thank Dr. Suvendu Das for his valuable suggestions in improving the quality of the manuscript. The authors appreciate the reviewers of the journal for their valuable comments and suggestions to improve the quality of the manuscript.

Anding, C., Brandt, R. D., and Ourisson, G. (1971). Sterol biosynthesis in Euglena gracilis Z. Sterol precursors in light-grown and dark-grown Euglena gracilis $Z$. Eur. J. Biochem. 24, 259-263. doi: 10.1111/j.1432-1033.1971.tb19679.x

Asa, P. B., Cao, Y., and Garry, R. F. (2000). Antibodies to squalene in Gulf War syndrome. Exp. Mol. Pathol. 68, 55-64. doi: 10.1006/exmp.1999.2295

Asa, P. B., Wilson, R. B., and Garry, R. F. (2002). Antibodies to squalene in recipients of anthrax vaccine. Exp. Mol. Pathol. 73, 19-27. doi: 10.1006/exmp.2002.2429

Bada, J. C., León-Camacho, M., Prieto, M., and Alonso, L. (2004). Characterization of oils of hazelnuts from Asturias, Spain. Eur. J. Lipid Sci. Technol. 106, 294-300. doi: 10.1002/ejlt.200300922 
Banerjee, A., Sharma, R., Chisti, Y., and Banerjee, U. C. (2002). Botryococcus braunii: a renewable source of hydrocarbons and other chemicals. Crit. Rev. Biotechnol. 22, 245-279. doi: 10.1080/07388550290789513

Basson, M. E., Thorsness, M., and Rine, J. (1986). Saccharomyces cerevisiae contains two functional genes encoding 3-hydroxy-3-methylglutarylcoenzyme A reductase. Proc. Natl. Acad. Sci. U.S.A. 83, 5563-5567. doi: $10.1073 /$ pnas.83.15.5563

Beltrán, G., Bucheli, M. E., Aguilera, M. P., Belaj, A., and Jimenez, A. (2016). Squalene in virgin olive oil: screening of variability in olive cultivars. Eur. J. Lipid Sci. Technol. 118, 1250-1253. doi: 10.1002/ejlt.201500295

Beveridge, T. H., Li, T. S., and Drover, J. C. (2002). Phytosterol content in American ginseng seed oil. J. Agric. Food Chem. 50, 744-750. doi: 10.1021/jf010701v

Bhattacharjee, P., Shukla, V. B., Singhal, R. S., and Kulkarni, P. R. (2001). Studies on fermentative production of squalene. World J. Microbiol. Biotechnol. 17, 811-816. doi: 10.1023/A:1013573912952

Bhattacharjee, P., and Singhal, R. S. (2003). Extraction of squalene from yeast by supercritical carbon dioxide. World J. Microbiol. Biotechnol. 19, 605-608. doi: 10.1023/A:1025146132281

Blagović, B., Rupčić, J., Mesarić, M., Georgiú, K., and Marić, V. (2001). Lipid composition of brewer's yeast. Food Technol. Biotechnol. 39, 175-181.

Bondioli, P., Mariani, C., Lanzani, A., Fedeli, E., and Muller, A. (1993). Squalene recovery from olive oil deodorizer distillates. J. Am. Oil Chem. Soc. 70, 763-766. doi: 10.1007/BF02542597

Budiyanto, A., Ahmed, N. U., Wu, A., Bito, T., Nikaido, O., Osawa, T., et al. (2000). Protective effect of topically applied olive oil against photocarcinogenesis following UVB exposure of mice. Carcinogenesis 21, 2085-2090. doi: 10.1093/carcin/21.11.2085

Bunch, A. W., and Harris, R. E. (1986). The manipulation of micro-organisms for the production of secondary metabolites. Biotechnol. Genet. Eng. Rev. 4, 117-144. doi: 10.1080/02648725.1986.10647825

Castelli, F., Sarpietro, M. G., Micieli, D., Stella, B., Rocco, F., and Cattel, L. (2007). Enhancement of gemcitabine affinity for biomembranes by conjugation with squalene: differential scanning calorimetry and Langmuir-Blodgett studies using biomembrane models. J. Colloid Interface Sci. 316, 43-52. doi: 10.1016/j.jcis.2007.07.064

Chang, M. H., Kim, H. J., Jahng, K. Y., and Hong, S. C. (2008). The isolation and characterization of Pseudozyma sp. JCC 207, a novel producer of squalene. Appl. Microbiol. Biotechnol. 78, 963-972. doi: 10.1007/s00253-008-1395-4

Chen, G., Fan, K. W., Lu, F. P., Li, Q., Aki, T., Chen, F., et al. (2010). Optimization of nitrogen source for enhanced production of squalene from thraustochytrid Aurantiochytrium sp. New Biotechnol. 27, 382-389. doi: 10.1016/j.nbt.2010.04.005

Cho, S., Choi, C. W., Lee, D. H., Won, C. H., Kim, S. M., Lee, S., et al. (2009). High-dose squalene ingestion increases type I procollagen and decreases ultraviolet-induced DNA damage in human skin in vivo but is associated with transient adverse effects. Clin. Exp. Dermatol. 34, 500-508. doi: 10.1111/j.1365-2230.2008.03133.x

Choi, S. Y., Lee, H. J., Choi, J., Kim, J., Sim, S. J., Um, Y., et al. (2016). Photosynthetic conversion of $\mathrm{CO}_{2}$ to farnesyl diphosphate-derived phytochemicals (amorpha-4, 11-diene and squalene) by engineered cyanobacteria. Biotechnol. Biofuels 9:202. doi: 10.1186/s13068-016-0617-8

Choi, S. Y., Wang, J. Y., Kwak, H. S., Lee, S. M., Um, Y., Kim, Y., et al. (2017). Improvement of squalene production from $\mathrm{CO}_{2}$ in Synechococcus elongatus PCC 7942 by metabolic engineering and scalable production in a photobioreactor. ACS Synth. Biol. 6, 1289-1295. doi: 10.1021/acssynbio.7b00083

Chubukov, V., Mukhopadhyay, A., Petzold, C. J., Keasling, J. D., and Martín, H. G. (2016). Synthetic and systems biology for microbial production of commodity chemicals. NPJ Syst. Biol. Appl. 2:16009. doi: 10.1038/npjsba.2016.9

Chung, H., Kim, T. W., Kwon, M., Kwon, I. C., and Jeong, S. Y. (2001). Oil components modulate physical characteristics and function of the natural oil emulsions as drug or gene delivery system. J. Controlled Release 71, 339-350. doi: 10.1016/S0168-3659(00)00363-1

Ciriminna, R., Pandarus, V., Béland, F., and Pagliaro, M. (2014). Catalytic hydrogenation of squalene to squalane. Org. Process Res. Dev. 18, 1110-1115. doi: $10.1021 /$ op 5002337

Cirmena, G., Franceschelli, P., Isnaldi, E., Ferrando, L., De Mariano, M., Ballestrero, A., et al. (2018). Squalene epoxidase as a promising metabolic target in cancer treatment. Cancer Lett. 425, 13-20. doi: 10.1016/j.canlet.2018. 03.034

Couvreur, P., Stella, B., Reddy, L. H., Hillaireau, H., Dubernet, C., Desmaële, D., et al. (2006). Squalenoyl nanomedicines as potential therapeutics. Nano Lett. 6, 2544-2548. doi: 10.1021/nl061942q

Czaplicki, S., Ogrodowska, D., Derewiaka, D., Tanska, M., and Zadernowski, R. (2011). Bioactive compounds in unsaponifiable fraction of oils from unconventional sources. Eur. J. Lipid Sci. Technol. 113, 1456-1464. doi: 10.1002/ejlt.201000410

Czaplicki, S., Ogrodowska, D., Zadernowski, R., and Derewiaka, D. (2012). Characteristics of biologically-active substances of amaranth oil obtained by various techniques. Pol. J. Food Nutr. Sci. 62, 235-239. doi: 10.2478/v10222-012-0054-8

Dai, Z., Liu, Y., Huang, L., and Zhang, X. (2012). Production of miltiradiene by metabolically engineered Saccharomyces cerevisiae. Biotechnol. Bioeng. 109, 2845-2853. doi: 10.1002/bit.24547

Dai, Z., Wang, B., Liu, Y., Shi, M., Wang, D., Zhang, X., et al. (2014). Producing aglycons of ginsenosides in bakers' yeast. Sci. Rep. 4:3698. doi: $10.1038 /$ srep03698

Das, B., Antoon, R., Tsuchida, R., Lotfi, S., Morozova, O., Farhat, W., et al. (2008). Squalene selectively protects mouse bone marrow progenitors against cisplatin and carboplatin-induced cytotoxicity in vivo without protecting tumor growth. Neoplasia 10, 1105-1119. doi: 10.1593/neo.08466

Das, B., Yeger, H., Baruchel, H., Freedman, M. H., Koren, G., and Baruchel, S. (2003). In vitro cytoprotective activity of squalene on a bone marrow versus neuroblastoma model of cisplatin-induced toxicity: implications in cancer chemotherapy. Eur. J. Cancer 39, 2556-2565. doi: 10.1016/j.ejca.2003. 07.002

Del Giudice, G., Fragapane, E., Bugarini, R., Hora, M., Henriksson, T., Palla, E., et al. (2006). Vaccines with the MF59 adjuvant do not stimulate antibody responses against squalene. Clin. Vaccine Immunol. 13, 1010-1013. doi: 10.1128/CVI.00191-06

Derewiaka, D., Szwed, E., and Wolosiak, R. (2014). Physicochemical properties and composition of lipid fraction of selected edible nuts. Pak. J. Bot. 46, 337-343.

Drozdíková, E., Garaiová, M., Csáky, Z., Obernauerová, M., and Hapala, I. (2015). Production of squalene by lactose-fermenting yeast Kluyveromyces lactis with reduced squalene epoxidase activity. Lett. Appl. Microbiol. 61, 77-84. doi: 10.1111/lam.12425

Dulvy, N. K., Baum, J. K., Clarke, S., Compagno, L. J., Cortés, E., Domingo, A., et al. (2008). You can swim but you can't hide: the global status and conservation of oceanic pelagic sharks and rays. Aquat. Conserv. 18, 459-482. doi: 10.1002 /aqc. 975

Dumont, M. J., and Narine, S. S. (2007). Characterization of flax and soybean soapstocks, and soybean deodorizer distillate by GCFID. J. Am. Oil Chem. Soc. 84, 1101-1105. doi: 10.1007/s11746-007-1154-1

Englund, E., Pattanaik, B., Ubhayasekera, S. J. K., Stensjö, K., Bergquist, J., and Lindberg, P. (2014). Production of squalene in Synechocystis sp. PCC 6803. PLoS ONE 9:e90270. doi: 10.1371/journal.pone.0090270

Fagundes, M. B., Vendruscolo, R. G., Maroneze, M. M., Barin, J. S., de Menezes, C. R., Zepka, L. Q., et al. (2018). Towards a sustainable route for the production of squalene using cyanobacteria. Waste Biomass Valorization 1-8. doi: 10.1007/s12649-017-0191-8

Fan, K. W., Aki, T., Chen, F., and Jiang, Y. (2010). Enhanced production of squalene in the thraustochytrid Aurantiochytrium mangrovei by medium optimization and treatment with terbinafine. World J. Microbiol. Biotechnol. 26, 1303-1309. doi: 10.1007/s11274-009-0301-2

Fang, J. Y., Fang, C. L., Liu, C. H., and Su, Y. H. (2008). Lipid nanoparticles as vehicles for topical psoralen delivery: solid lipid nanoparticles (SLN) versus nanostructured lipid carriers (NLC). Eur. J. Pharm. Biopharm. 70, 633-640. doi: 10.1016/j.ejpb.2008.05.008

Fernandes, G. D., Gómez-Coca, R. B., Pérez-Camino, M. D. C., Moreda, W., and Barrera-Arellano, D. (2017). Chemical characterization of major and minor compounds of nut oils: almond, hazelnut, and pecan nut. J. Chem. 2017:2609549. doi: 10.1155/2017/2609549

Fernández-Medarde, A., and Santos, E. (2011). Ras in cancer and developmental diseases. Genes Cancer 2, 344-358. doi: 10.1177/1947601911411084

Fornairon-Bonnefond, C., Demaretz, V., Rosenfeld, E., and Salmon, J. M. (2002). Oxygen addition and sterol synthesis in Saccharomyces 
cerevisiae during enological fermentation. J. Biosci. Bioeng. 93, 176-182. doi: 10.1016/S1389-1723(02)80011-1

Frega, N., Bocci, F., and Lercker, G. (1992). Direct gas chromatographic analysis of the unsaponifiable fraction of different oils with a polar capillary column. J. Am. Oil Chem. Soc. 69, 447-450. doi: 10.1007/BF02540946

Furubayashi, M., Li, L., Katabami, A., Saito, K., and Umeno, D. (2014a). Construction of carotenoid biosynthetic pathways using squalene synthase. FEBS Lett. 588, 436-442. doi: 10.1016/j.febslet.2013.12.003

Furubayashi, M., Li, L., Katabami, A., Saito, K., and Umeno, D. (2014b). Directed evolution of squalene synthase for dehydrosqualene biosynthesis. FEBS Lett. 588, 3375-3381. doi: 10.1016/j.febslet.2014.07.028

Gabás-Rivera, C., Barranquero, C., Martínez-Beamonte, R., Navarro, M. A., Surra, J. C., and Osada, J. (2014). Dietary squalene increases high density lipoproteincholesterol and paraoxonase 1 and decreases oxidative stress in mice. PLOS ONE 9:e104224. doi: 10.1371/journal.pone.0104224

Garaiová, M., Zambojová, V., Šimová, Z., Griač, P., and Hapala, I. (2014). Squalene epoxidase as a target for manipulation of squalene levels in the yeast Saccharomyces cerevisiae. FEMS Yeast Res. 14, 310-323. doi: 10.1111/1567-1364.12107

Ghimire, G. P., Lee, H. C., and Sohng, J. K. (2009). Improved squalene production via modulation of the methyl-erythritol 4-phosphate pathway and heterologous expression of genes from Streptomyces peucetius ATCC 27952 in Escherichia coli. Appl. Environ. Microbiol. 75, 7291-7293. doi: 10.1128/AEM.01402-09

Ghimire, G. P., Thuan, N. H., Koirala, N., and Sohng, J. K. (2016). Advances in biochemistry and microbial production of squalene and its derivatives. $J$. Microbiol. Biotechnol. 26, 441-451. doi: 10.4014/jmb.1510.10039

Giacometti, J., and Milin, C. (2001). Composition and qualitative characteristics of virgin olive oils produced in northern Adriatic region, Republic of Croatia. Grasas Aceites 52, 397-402. doi: 10.3989/gya.2001.v52.i6.350

Global Market Insights (2016). Squalene Market Size by Source, by Application, Industry Analysis Report, Regional Outlook, Application Potential, Price Trends, Competitive Market Share \& Forecast, 2015-2022. Available online at: https://www.gminsights.com/industry-analysis/squalene-market (Accessed September 16, 2018).

Goh, S. H., Choo, Y. M., and Ong, S. H. (1985). Minor constituents of palm oil. J. Am. Oil Chem. Soc. 62, 237-240. doi: 10.1007/BF02541384

Gohil, N., Panchasara, H., Patel, S., Ramírez-García, R., and Singh, V. (2017). Book review: recent advances in yeast metabolic engineering. Front. Bioeng. Biotechnol. 5:71. doi: 10.3389/fbioe.2017.00071

Goldberg, I., and Shechter, I. (1978). Occurrence of squalene in methanol-grown bacteria. J. Bacteriol. 135, 717-720.

Grigoriadou, D., Androulaki, A., Psomiadou, E., and Tsimidou, M. Z. (2007). Solid phase extraction in the analysis of squalene and tocopherols in olive oil. Food Chem. 105, 675-680. doi: 10.1016/j.foodchem.2006.12.065

Gronseth, G. S. (2005). Gulf war syndrome: a toxic exposure? A systematic review. Neurol. Clin. 23, 523-540. doi: 10.1016/j.ncl.2004.12.011

Gunawan, S., Kasim, N. S., and Ju, Y. H. (2008). Separation and purification of squalene from soybean oil deodorizer distillate. Sep. Purif. Technol. 60, 128-135. doi: 10.1016/j.seppur.2007.08.001

Günes, F. E. (2013). Medical use of squalene as a natural antioxidant. Clin. Exp. Health Sci. 3, 220-228. doi: 10.5455/musbed.20131213100404

Gutfinger, T., and Letan, A. (1974). Studies of unsaponifiables in several vegetable oils. Lipids 9, 658-663. doi: 10.1007/BF02532171

Han, J. Y., Seo, S. H., Song, J. M., Lee, H., and Choi, E. S. (2018). High-level recombinant production of squalene using selected Saccharomyces cerevisiae strains. J. Ind. Microbiol. Biotechnol. 45, 239-251. doi: 10.1007/s10295-018-2018-4

He, H. P., and Corke, H. (2003). Oil and squalene in amaranthus grain and leaf. J. Agric. Food Chem. 51, 7913-7920. doi: 10.1021/jf030489q

He, H. P., Corke, H., and Cai, J. G. (2003). Supercritical carbon dioxide extraction of oil and squalene from Amaranthus grain. J. Agric. Food Chem. 51, 7921-7925. doi: 10.1021/jf030488y

Hensel, M. T., Marshall, J. D., Dorwart, M. R., Heeke, D. S., Rao, E., Tummala, P., et al. (2017). Prophylactic herpes simplex virus 2 (HSV-2) vaccines adjuvanted with stable emulsion and toll-like receptor 9 agonist induce a robust HSV-2-specific cell-mediated immune response, protect against symptomatic disease, and reduce the latent viral reservoir. J. Virol. 91, e02257-e02216. doi: 10.1128/JVI.02257-16
Hoang, L. A. T., Nguyen, H. C., Le, T. T., Hoang, T. H. Q., Pham, V. N., Hoang, M. H. T., et al. (2018). Different fermentation strategies by Schizochytrium mangrovei strain pq6 to produce feedstock for exploitation of squalene and omega-3 fatty acids. J. Phycol. 54, 550-556. doi: 10.1111/jpy. 12757

Hoang, M. H., Ha, N. C., Tam, L. T., Anh, H. T. L., Thu, N. T. H., and Hong, D. D. (2014). Extraction of squalene as value-added product from the residual biomass of Schizochytrium mangrovei PQ6 during biodiesel producing process. J. Biosci. Bioeng. 118, 632-639. doi: 10.1016/j.jbiosc.2014.05.015

Hon, K. L., Kung, J. S. C., Ng, W. G. G., and Leung, T. F. (2018). Emollient treatment of atopic dermatitis: latest evidence and clinical considerations. Drugs Context 7:212530. doi: 10.7573/dic.212530

Huang, Y. Y., Jian, X. X., Lv, Y. B., Nian, K. Q., Gao, Q., Chen, J., et al. (2018). Enhanced squalene biosynthesis in Yarrowia lipolytica based on metabolically engineered acetyl-CoA metabolism. J. Biotechnol. 281, 106-114. doi: 10.1016/j.jbiotec.2018.07.001

Huang, Z. R., Lin, Y. K., and Fang, J. Y. (2009). Biological and pharmacological activities of squalene and related compounds: potential uses in cosmetic dermatology. Molecules 14, 540-554. doi: 10.3390/molecules 14010540

Hull, C. M., Loveridge, E. J., Rolley, N. J., Donnison, I. S., Kelly, S. L., and Kelly, D. E. (2014). Co-production of ethanol and squalene using a Saccharomyces cerevisiae ERG1 (squalene epoxidase) mutant and agro-industrial feedstock. Biotechnol. Biofuels 7:133. doi: 10.1186/s13068-014-0133-7

Ioannides, C., Lewis, V., and David, F. (2004). Cytochromes P450 in the bioactivation of chemicals. Curr. Top. Med. Chem. 4, 1767-1788. doi: 10.2174/1568026043387188

Ivanova, S., Tonchev, V., Yokoi, N., Yappert, M. C., Borchman, D., and Georgiev, G. A. (2015). Surface properties of squalene/meibum films and NMR confirmation of squalene in tears. Int. J. Mol. Sci. 16, 21813-21831. doi: 10.3390/ijms160921813

Jandrositz, A., Turnowsky, F., and Högenauer, G. (1991). The gene encoding squalene epoxidase from Saccharomyces cerevisiae: cloning and characterization. Gene 107, 155-160. doi: 10.1016/0378-1119(91)90310-8

Jiang, Y., Fan, K. W., Tsz-Yeung Wong, R., and Chen, F. (2004). Fatty acid composition and squalene content of the marine microalga Schizochytrium mangrovei. J. Agric. Food Chem. 52, 1196-1200. doi: 10.1021/jf035004c

Jullesson, D., David, F., Pfleger, B., and Nielsen, J. (2015). Impact of synthetic biology and metabolic engineering on industrial production of fine chemicals. Biotechnol. Adv. 33, 1395-1402. doi: 10.1016/j.biotechadv.2015.02.011

Kajikawa, M., Kinohira, S., Ando, A., Shimoyama, M., Kato, M., and Fukuzawa, H. (2015). Accumulation of squalene in a microalga Chlamydomonas reinhardtii by genetic modification of squalene synthase and squalene epoxidase genes. PLoS ONE 10:e0120446. doi: 10.1371/journal.pone.0120446

Kamimura, H., Koga, N., Oguri, K., and Yoshimura, H. (1992). Enhanced elimination of theophylline, phenobarbital and strychnine from the bodies of rats and mice by squalane treatment. J. Pharmacobio-Dyn. 15, 215-221. doi: 10.1248/bpb1978.15.215

Kamimura, N., Hidaka, M., Masaki, H., and Uozumi, T. (1994). Construction of squalene-accumulating Saccharomyces cerevisiae mutants by gene disruption through homologous recombination. Appl. Microbiol. Biotechnol. 42, 353-357. doi: $10.1007 / \mathrm{s} 002530050262$

Kaneko, T., and Tabata, S. (1997). Complete genome structure of the unicellular cyanobacterium Synechocystis sp. PCC6803. Plant Cell Physiol. 38, 1171-1176. doi: 10.1093/oxfordjournals.pcp.a029103

Kasai, H., Katsuta, A., Sekiguchi, H., Matsuda, S., Adachi, K., Shindo, K., et al. (2007). Rubritalea squalenifaciens sp. nov., a squalene-producing marine bacterium belonging to subdivision 1 of the phylum 'Verrucomicrobia'. Int. J. Syst. Evol. Microbiol. 57, 1630-1634. doi: 10.1099/ijs.0.65010-0

Katabami, A., Li, L., Iwasaki, M., Furubayashi, M., Saito, K., and Umeno, D. (2015). Production of squalene by squalene synthases and their truncated mutants in Escherichia coli. J. Biosci. Bioeng. 119, 165-171. doi: 10.1016/j.jbiosc.2014.07.013

Kaya, K., Nakazawa, A., Matsuura, H., Honda, D., Inouye, I., and Watanabe, M. M. (2011). Thraustochytrid Aurantiochytrium sp. $18 \mathrm{~W}-13 \mathrm{a}$ accumulates high amounts of squalene. Biosci. Biotechnol. Biochem. 75, 2246-2248. doi: $10.1271 /$ bbb. 110430

Keasling, J. D. (2010). Manufacturing molecules through metabolic engineering. Science 330, 1355-1358. doi: 10.1126/science.1193990 
Kedl, J. D., and Kedl, R. M. (2015). How squalene GLAdly helps generate antigenspecific $\mathrm{T}$ cells via antigen-carrying neutrophils and IL-18. Eur. J. Immunol. 45, 376-379. doi: 10.1002/eji.201445379

Kelly, G. S. (1999). Squalene and its potential clinical uses. Altern. Med. Rev. 4, 29-36.

Kim, S. K., and Karadeniz, F. (2012). "Biological importance and applications of squalene and squalane," in Advances in Food and Nutrition Research, Vol. 65. ed S. K. Kim (Walthum, MA: Academic Press), 223-233.

Kim, Y. J., Kim, T. W., Chung, H., Kwon, I. C., Sung, H. C., and Jeong, S. Y. (2003). The effects of serum on the stability and the transfection activity of the cationic lipid emulsion with various oils. Int. J. Pharm. 252, 241-252. doi: 10.1016/S0378-5173(02)00676-2

Kohno, Y., Egawa, Y., Itoh, S., Nagaoka, S. I., Takahashi, M., and Mukai, K. (1995). Kinetic study of quenching reaction of singlet oxygen and scavenging reaction of free radical by squalene in n-butanol. Biochim. Biophys. Acta 1256, 52-56. doi: 10.1016/0005-2760(95)00005-W

Kopicová, Z., and Vavreinová, S. (2007). Occurrence of squalene and cholesterol in various species of Czech freshwater fish. Czech. J. Food Sci. 25, 195-201. doi: $10.17221 / 733-C J F S$

Kwak, S., Kim, S. R., Xu, H., Zhang, G. C., Lane, S., Kim, H., et al. (2017). Enhanced isoprenoid production from xylose by engineered Saccharomyces cerevisiae. Biotechnol. Bioeng. 114, 2581-2591. doi: 10.1002/bit.26369

Lanzón, A., Albi, T., Cert, A., and Gracián, J. (1994). The hydrocarbon fraction of virgin olive oil and changes resulting from refining. J. Am. Oil Chem. Soc. 71, 285-291. doi: 10.1007/BF02638054

Lau, H. L., Puah, C. W., Choo, Y. M., Ma, A. N., and Chuah, C. H. (2005). Simultaneous quantification of free fatty acids, free sterols, squalene, and acylglycerol molecular species in palm oil by high-temperature gas chromatography-flame ionization detection. Lipids 40, 523-528. doi: 10.1007/s11745-005-1413-1

Li, Q., Chen, G. Q., Fan, K. W., Lu, F. P., Aki, T., and Jiang, Y. (2009). Screening and characterization of squalene-producing thraustochytrids from Hong Kong mangroves. J. Agric. Food Chem. 57, 4267-4272. doi: 10.1021/jf9003972

Lippi, G., Targher, G., and Franchini, M. (2010). Vaccination, squalene and anti-squalene antibodies: facts or fiction? Eur. J. Inter. Med. 21, 70-73. doi: 10.1016/j.ejim.2009.12.001

Liu, G. C., Ahrens, E. H., Schreibman, P. H., and Crouse, J. R. (1976). Measurement of squalene in human tissues and plasma: validation and application. J. Lipid Res. 17, 38-45.

Lozano-Grande, M. A., Gorinstein, S., Espitia-Rangel, E., Dávila-Ortiz, G., and Martínez-Ayala, A. L. (2018). Plant sources, extraction methods, and uses of squalene. Int. J. Agron. 2018:1829160. doi: 10.1155/2018/1829160

Lyon, C.K., and Becker, R. (1987). Extraction and refining of oil from amaranth seed. J. Am. Oil Chem. Soc. 64, 233-236. doi: 10.1007/bf02542008

Mackowiak, B., and Wang, H. (2016). Mechanisms of xenobiotic receptor activation: direct vs. indirect. Biochim. Biophys. Acta 1859, 1130-1140. doi: 10.1016/j.bbagrm.2016.02.006

Maguire, L. S., O'Sullivan, S. M., Galvin, K., O'Connor, T. P., and O’Brien, N. M. (2004). Fatty acid profile, tocopherol, squalene and phytosterol content of walnuts, almonds, peanuts, hazelnuts and the macadamia nut. Int. J. Food Sci. Nutr. 55, 171-178. doi: 10.1080/09637480410001725175

Mantzouridou, F., Naziri, E., and Tsimidou, M. Z. (2009). Squalene versus ergosterol formation using Saccharomyces cerevisiae: combined effect of oxygen supply, inoculum size, and fermentation time on yield and selectivity of the bioprocess. J. Agric. Food Chem. 57, 6189-6198. doi: 10.1021/jf900673n

Mantzouridou, F., and Tsimidou, M. Z. (2010). Observations on squalene accumulation in Saccharomyces cerevisiae due to the manipulation of HMG2 and ERG6. FEMS Yeast Res. 10, 699-707. doi: $10.1111 / \mathrm{j} .1567-1364.2010 .00645 . \mathrm{x}$

Manzi, P., Panfili, G., Esti, M., and Pizzoferrato, L. (1998). Natural antioxidants in the unsaponifiable fraction of virgin olive oils from different cultivars. J. Sci. Food Agric. 77, 115-120. doi: 10.1002/(SICI)1097-0010(199805)77:1<115::AID-JSFA13>3.0.CO;2-N

Mao, X., Liu, Z., Sun, J., and Lee, S. Y. (2017). Metabolic engineering for the microbial production of marine bioactive compounds. Biotechnol. Adv. 35, 1004-1021. doi: 10.1016/j.biotechadv.2017.03.001

Martin, C. H., Nielsen, D. R., Solomon, K. V., and Prather, K. L. J. (2009). Synthetic metabolism: engineering biology at the protein and pathway scales. Chem. Biol. 16, 277-286. doi: 10.1016/j.chembiol.2009.01.010
Matthaus, B., and Özcan, M. M. (2014). Fatty acid, tocopherol and squalene contents of Rosaceae seed oils. Bot. Stud. 55:48. doi: 10.1186/s40529-014-0048-4

Matyas, G. R., Rao, M., Pittman, P. R., Burge, R., Robbins, I. E., Wassef, N. M., et al. (2004). Detection of antibodies to squalene: III. Naturally occurring antibodies to squalene in humans and mice. J. Immunol. Meth. 286, 47-67. doi: 10.1016/j.jim.2003.11.002

Mudiyanselage, S. E., Elsner, P., Thiele, J. J., and Hamburger, M. (2003). Ultraviolet A induces generation of squalene monohydroperoxide isomers in human sebum and skin surface lipids in vitro and in vivo. J. Invest. Dermatol. 120, 915-922. doi: 10.1046/j.1523-1747.2003.12233.x

Murakoshi, M., Nishino, H., Tokuda, H., Iwashima, A., Okuzumi, J., Kitano, H., et al. (1992). Inhibition by squalene of the tumor promoting activity of $12-\mathrm{O}-$ Tetradecanoylphorbol-13-acetate in mouse skin carcinogenesis. Int. J. Cancer 52, 950-952. doi: 10.1002/ijc.2910520620

Nakagawa, M., Yamaguchi, T., Fukawa, H., Ogata, J., Komiyama, S., Akiyama, S. I., et al. (1985). Potentiation by squalene of the cytotoxicity of anticancer agents against cultured mammalian cells and murine tumor. Jpn. J. Cancer Res. $76,315-320$

Nakazawa, A., Kokubun, Y., Matsuura, H., Yonezawa, N., Kose, R., Yoshida, M., et al. (2014). TLC screening of thraustochytrid strains for squalene production. J. Appl. Phycol. 26, 29-41. doi: 10.1007/s10811-013-0080-x

Nakazawa, A., Matsuura, H., Kose, R., Kato, S., Honda, D., Inouye, I., et al. (2012). Optimization of culture conditions of the thraustochytrid Aurantiochytrium sp. strain 18W-13a for squalene production. Bioresour. Technol. 109, 287-291. doi: 10.1016/j.biortech.2011.09.127

Naz, S., Sherazi, S. T. H., Talpur, F. N., Kara, H., Uddin, S., and Khaskheli, R. (2014). Chemical characterization of canola and sunflower oil deodorizer distillates. Pol. J. Food Nutr. Sci. 64, 115-120. doi: 10.2478/pjfns-2013-0008

Naziri, E., Mantzouridou, F., and Tsimidou, M. Z. (2011a). Enhanced squalene production by wild-type Saccharomyces cerevisiae strains using safe chemical means. J. Agric. Food Chem. 59, 9980-9989. doi: 10.1021/jf201328a

Naziri, E., Mantzouridou, F., and Tsimidou, M. Z. (2011b). Squalene resources and uses point to the potential of biotechnology. Lipid Technol. 23, 270-273. doi: 10.1002/lite.201100157

Naziri, E., Mantzouridou, F., and Tsimidou, M. Z. (2012). Recovery of squalene from wine lees using ultrasound assisted extraction - a feasibility study. J. Agric. Food Chem. 60, 9195-9201. doi: 10.1021/jf301059y

Nenadis, N., and Tsimidou, M. (2002). Determination of squalene in olive oil using fractional crystallization for sample preparation. J. Am. Oil Chem. Soc. 79, 257-259. doi: 10.1007/s11746-002-0470-1

Newmark, H. L. (1997). Squalene, olive oil, and cancer risk: a review and hypothesis. Cancer Epidemiol. Prev. Biomarker 6, 1101-1103.

Nicolaides, N. (1974). Skin lipids: their biochemical uniqueness. Science 186, 19-26. doi: 10.1126/science.186.4158.19

Nicolaos, G., Crauste-Manciet, S., Farinotti, R., and Brossard, D. (2003). Improvement of cefpodoxime proxetil oral absorption in rats by an oil-in-water submicron emulsion. Int. J. Pharm. 263, 165-171. doi: 10.1016/S0378-5173(03)00365-X

Nikkari, T., Schreibman, P. H., and Ahrens, E. H. (1974). In vivo studies of sterol and squalene secretion by human skin. J. Lipid Res. 15, 563-573.

Okuda, M., Yoshiike, T., and Ogawa, H. (2002). Detergent-induced epidermal barrier dysfunction and its prevention. J. Dermatol. Sci. 30, 173-179. doi: 10.1016/S0923-1811(02)00106-8

Omiecinski, C. J., Vanden Heuvel, J. P., Perdew, G. H., and Peters, J. M. (2011). Xenobiotic metabolism, disposition, and regulation by receptors: from biochemical phenomenon to predictors of major toxicities. Toxicol. Sci. 120, S49-S75. doi: 10.1093/toxsci/kfq338

Owen, R. W., Giacosa, A., Hull, W. E., Haubner, R., Würtele, G., Spiegelhalder, B., et al. (2000a). Olive-oil consumption and health: the possible role of antioxidants. Lancet Oncol. 1, 107-112. doi: 10.1016/S1470-2045(00) $00015-2$

Owen, R. W., Haubner, R., Würtele, G., Hull, W. E., Spiegelhalder, B., and Bartsch, H. (2004). Olives and olive oil in cancer prevention. Eur. J. Cancer Prev. 13, 319-326. doi: 10.1097/01.cej.0000130221.19480.7e

Owen, R. W., Mier, W., Giacosa, A., Hull, W. E., Spiegelhalder, B., and Bartsch, H. (2000b). Phenolic compounds and squalene in olive oils: the concentration and antioxidant potential of total phenols, simple phenols, secoiridoids, lignansand squalene. Food Chem. Toxicol. 38, 647-659. doi: 10.1016/S0278-6915(00)00061-2 
Pan, J. J., Solbiati, J. O., Ramamoorthy, G., Hillerich, B. S., Seidel, R. D., Cronan, J. E., et al. (2015). Biosynthesis of squalene from farnesyl diphosphate in bacteria: three steps catalyzed by three enzymes. ACS Cent. Sci. 1, 77-82. doi: 10.1021/acscentsci.5b00115

Panchasara, H., Patel, S., Gohil, N., and Singh, V. (2018). "Biosynthetic pathway for production of renewable biofuels," in Biofuels. ed V. Mittal (Orange, FL: Central West Publishing), 63-86.

Paramasivan, K., and Mutturi, S. (2017). Regeneration of NADPH coupled with HMG-CoA reductase activity increases squalene synthesis in Saccharomyces cerevisiae. J. Agric. Food Chem. 65, 8162-8170. doi: 10.1021/acs.jafc.7b02945

Pasquale, A. D., Preiss, S., Silva, F. T. D., and Garçon, N. (2015). Vaccine adjuvants: from 1920 to 2015 and beyond. Vaccines 3, 320-343. doi: $10.3390 /$ vaccines 3020320

Patra, K. P., Li, F., Carter, D., Gregory, J. A., Baga, S., Reed, S. G., et al. (2015). Algae-produced malaria transmission-blocking vaccine candidate Pfs 25 formulated with a human use-compatible potent adjuvant induces high affinity antibodies that block Plasmodium falciparum infection of mosquitoes. Infect. Immun. 83, 1799-1808. doi: 10.1128/IAI.02980-14

Peramo, A., Mura, S., Yesylevskyy, S. O., Cardey, B., Sobot, D., Denis, S., et al. (2018). Squalene versus cholesterol: Which is the best nanocarrier for the delivery to cells of the anticancer drug gemcitabine? C. R. Chim. 21, 974-986. doi: 10.1016/j.crci.2018.02.008

Pham, D. M., Boussouira, B., Moyal, D., and Nguyen, Q. L. (2015). Oxidization of squalene, a human skin lipid: a new and reliable marker of environmental pollution studies. Int. J. Cosmet. Sci. 37, 357-365. doi: 10.1111/ics.12208

Pili, B., Bourgaux, C., Amenitsch, H., Keller, G., Lepêtre-Mouelhi, S., Desmaële, D., et al. (2010). Interaction of a new anticancer prodrug, gemcitabine-squalene, with a model membrane: Coupled DSC and XRD study. Biochim. Biophys. Acta 1798, 1522-1532. doi: 10.1016/j.bbamem.2010.04.011

Pokkanta, P., Sookwong, P., Tanang, M., Setchaiyan, S., Boontakham, P., and Mahatheeranont, S. (2019). Simultaneous determination of tocols, $\gamma$-oryzanols, phytosterols, squalene, cholecalciferol and phylloquinone in rice bran and vegetable oil samples. Food Chem. 271, 630-638. doi: 10.1016/j.foodchem.2018.07.225

Polakowski, T., Stahl, U., and Lang, C. (1998). Overexpression of a cytosolic hydroxymethylglutaryl-CoA reductase leads to squalene accumulation in yeast. Appl. Microbiol. Biotechnol. 49, 66-71. doi: 10.1007/s002530051138

Popa, I., Băbeanu, N. E., Nită, S., and Popa, O. (2014). Squalene - natural resources and applications. Farmacia 62, 840-862.

Popa, O., Băbeanu, N. E., Popa, I., Nită, S., and Dinu-Pârvu, C. E. (2015). Methods for obtaining and determination of squalene from natural sources. Biomed. Res. Int. 2015:367202. doi: 10.1155/2015/367202

Pora, B., Qian, Y., Caulier, B., Comini, S., Looten, P., Segueilha, L., et al. (2014). Method for the Preparation and Extraction of Squalene From Microalgae. U.S. Patent Appl. 14/118,641. Bucharest: Printech Publishing House.

Posada, L. R., Shi, J., Kakuda, Y., and Xue, S. J. (2007). Extraction of tocotrienols from palm fatty acid distillates using molecular distillation. Sep. Purif. Technol. 57, 220-229. doi: 10.1016/j.seppur.2007.04.016

Prakash, D., Verma, S., Bhatia, R., and Tiwary, B. N. (2011). Risks and precautions of genetically modified organisms. ISRN Ecol. 2011:369573. doi: $10.5402 / 2011 / 369573$

Rabinovitch-Deere, C. A., Oliver, J. W., Rodriguez, G. M., and Atsumi, S. (2013). Synthetic biology and metabolic engineering approaches to produce biofuels. Chem. Rev. 113, 4611-4632. doi: 10.1021/cr300361t

Rahman, A. M., Yusuf, S. W., and Ewer, M. S. (2007). Anthracycline-induced cardiotoxicity and the cardiac-sparing effect of liposomal formulation. Int. J. Nanomed. 2, 567-583.

Ramírez-García, R., Gohil, N., and Singh, V. (2018). "Recent advances, challenges, and opportunities in bioremediation of hazardous materials," in Phytomanagement of Polluted Sites, eds V. C. Pandey, K. Bauddh (Amsterdam: Elsevier Inc.), 517-568.

Rani, A., Meghana, R., and Kush, A. (2018). Squalene production in the cell suspension cultures of Indian sandalwood (Santalum album L.) in shake flasks and air lift bioreactor. Plant Cell Tissue Organ Cult. 135, 155-167. doi: $10.1007 / \mathrm{s} 11240-018-1452-3$

Rao, C. V., Newmark, H. L., and Reddy, B. S. (1998). Chemopreventive effect of squalene on colon cancer. Carcinogenesis 19, 287-290. doi: 10.1093/carcin/19.2.287
Rasool, A., Ahmed, M. S., and Li, C. (2016a). Overproduction of squalene synergistically downregulates ethanol production in Saccharomyces cerevisiae. Chem. Eng. Sci. 152, 370-380. doi: 10.1016/j.ces.2016.06.014

Rasool, A., Zhang, G., Li, Z., and Li, C. (2016b). Engineering of the terpenoid pathway in Saccharomyces cerevisiae co-overproduces squalene and the non-terpenoid compound oleic acid. Chem. Eng. Sci. 152, 457-467. doi: 10.1016/j.ces.2016.06.004

Rehman, M. U., Tahir, M., Ali, F., Qamar, W., Lateef, A., Khan, R., et al. (2012). Cyclophosphamide-induced nephrotoxicity, genotoxicity, and damage in kidney genomic DNA of Swiss albino mice: the protective effect of Ellagic acid. Mol. Cell. Biochem. 365, 119-127. doi: 10.1007/s11010-012-1250-x

Richter, E., Fichtl, B., and Schäfer, S. G. (1982). Effects of dietary paraffin, squalane and sucrose polyester on residue disposition and elimination of hexachlorobenzene in rats. Chem. Biol. Interact. 40, 335-344. doi: 10.1016/0009-2797(82)90156-9

Richter, E., and Schäfer, S. G. (1982). Effect of squalane on hexachlorobenzene (HCB) concentrations in tissues of mice. J. Environ. Sci. Health B 17, 195-203. doi: $10.1080 / 03601238209372313$

Rissmann, R., Oudshoorn, M. H., Kocks, E., Hennink, W. E., Ponec, M., and Bouwstra, J. A. (2008). Lanolin-derived lipid mixtures mimic closely the lipid composition and organization of vernix caseosa lipids. Biochim. Biophys. Acta 1778, 2350-2360. doi: 10.1016/j.bbamem.2008.06.017

Ronco, A. L., and De Stéfani, E. (2013). Squalene: a multi-task link in the crossroads of cancer and aging. Funct. Food Health Dis. 3, 462-476. doi: $10.31989 /$ ffhd.v3i12.30

Rosales-García, T., Jiménez-Martínez, C., Cardador-Martínez, A., Martín-del Campo, S. T., Galicia-Luna, L. A., Téllez-Medina, D. I., et al. (2017b). Squalene extraction by supercritical fluids from traditionally puffed Amaranthus hypochondriacus seeds. J. Food Qual. 2017:6879712. doi: 10.1155/2017/ 6879712

Rosales-Garcia, T., Jimenez-Martinez, C., and Dávila-Ortiz, G. (2017a). Squalene extraction: Biological sources and extraction methods. Int. J. Environ. Agric. Biotechnol. 2, 1662-1670. doi: 10.22161/ijeab/2.4.26

Rudzinska, M., Górnaś, P., Raczyk, M., and Soliven, A. (2017). Sterols and squalene in apricot (Prunus armeniaca L.) kernel oils: the variety as a key factor. Nat. Prod. Res. 31, 84-88. doi: 10.1080/14786419.2015.1135146

Rukmini, C., and Raghuram, T. C. (1991). Nutritional and biochemical aspects of the hypolipidemic action of rice bran oil: a review. J. Am. Coll. Nutr. 10, 593-601. doi: 10.1080/07315724.1991.10718181

Saha, B. C. (2003). "Commodity chemicals production by fermentation: an overview," in Fermentation Biotechnology-ACS Symposium Series. ed B. C. Saha (Washington, DC: American Chemical Society) 862, 3-20.

Salvo, A., La Torre, G. L., Di Stefano, V., Capocchiano, V., Mangano, V., Saija, E., et al. (2017). Fast UPLC/PDA determination of squalene in Sicilian PDO pistachio from Bronte: optimization of oil extraction method and analytical characterization. Food Chem. 221, 1631-1636. doi: $10.1016 /$ j.foodchem.2016.10.126

Sanchez, S., and Demain, A. L. (2008). Metabolic regulation and overproduction of primary metabolites. Microbial. Biotechnol. 1, 283-319. doi: 10.1111/j.1751-7915.2007.00015.x

Sánchez-Quesada, C., López-Biedma, A., Toledo, E., and Gaforio, J. J. (2018). Squalene stimulates a key innate immune cell to foster wound healing and tissue repair. Evid. Based Complement Alternat. Med. 2018:9473094. doi: $10.1155 / 2018 / 9473094$

Saunders, R. M., and Becker, R. (1984). "Amaranthus: a potential food and feed resource," in Advances in Cereal Science and Technology. ed Y. Pomeranz (St. Paul: American Association of Cereal Chemists), 357-397.

Seltenrich, N. (2015). New link in the food chain? Marine plastic pollution and seafood safety. Environ. Health Perspect. 123, A34-A41. doi: 10.1289/ehp.123-A34

Senthilkumar, S., Devaki, T., Manohar, B. M., and Babu, M. S. (2006a). Effect of squalene on cyclophosphamide-induced toxicity. Clin. Chim. Acta 364, 335-342. doi: 10.1016/j.cca.2005.07.032

Senthilkumar, S., Yogeeta, S. K., Subashini, R., and Devaki, T. (2006b). Attenuation of cyclophosphamide induced toxicity by squalene in experimental rats. Chem. Biol. Interact. 160, 252-260. doi: 10.1016/j.cbi.2006.02.004

Sethi, A., Kaur, T., Malhotra, S. K., and Gambhir, M. L. (2016). Moisturizers: the slippery road. Indian, J. Dermatol. 61, 279-287. doi: 10.4103/0019-5154.182427 
Seubert, A., Monaci, E., Pizza, M., O’Hagan, D. T., and Wack, A. (2008). The adjuvants aluminum hydroxide and MF59 induce monocyte and granulocyte chemoattractants and enhance monocyte differentiation toward dendritic cells. J. Immunol. 180, 5402-5412. doi: 10.4049/jimmunol.180.8.5402

Sherazi, S. T. H., and Mahesar, S. A. (2016). Vegetable oil deodorizer distillate: a rich source of the natural bioactive components. J. Oleo Sci. 65, 957-966. doi: $10.5650 /$ jos.ess 16125

Singh, V. (2014). Recent advancements in synthetic biology: current status and challenges. Gene 535, 1-11. doi: 10.1016/j.gene.2013.11.025

Singh, V., Braddick, D., and Dhar, P. K. (2017). Exploring the potential of genome editing CRISPR-Cas9 technology. Gene 599, 1-18. doi: 10.1016/j.gene.2016.11.008

Singh, V., Chaudhary, D. K., Mani, I., and Dhar, P. K. (2016). Recent advances and challenges of the use of cyanobacteria towards the production of biofuels. Renewable Sustainable Energy Rev. 60, 1-10. doi: 10.1016/j.rser.2016.01.099

Singh, V., Gohil, N., Ramírez García, R., Braddick, D., and Fofié, C. K. (2018). Recent advances in CRISPR-Cas9 genome editing technology for biological and biomedical investigations. J. Cell. Biochem. 119, 81-94. doi: 10.1002/jcb.26165

Singh, V., Mani, I., Chaudhary, D. K., and Dhar, P. K. (2014). Metabolic engineering of biosynthetic pathway for production of renewable biofuels. Appl. Biochem. Biotechnol. 172, 1158-1171. doi: 10.1007/s12010-013-0606-3

Smith, T. J. (2000). Squalene: potential chemopreventive agent. Expert Opin. Invest. Drugs 9, 1841-1848. doi: 10.1517/13543784.9.8.1841

Song, X., Wang, X., Tan, Y., Feng, Y., Li, W., and Cui, Q. (2015). High production of squalene using a newly isolated yeast-like strain Pseudozyma sp. SD301. J. Agric. Food Chem. 63, 8445-8451. doi: 10.1021/acs.jafc.5b03539

Spanova, M., and Daum, G. (2011). Squalene-biochemistry, molecular biology, process biotechnology, and applications. Eur. J. Lipid Sci. Technol. 113, 1299-1320. doi: 10.1002/ejlt.201100203

Stelzner, J. J., Behrens, M., Behrens, S. E., and Mäder, K. (2018). Squalene containing solid lipid nanoparticles, a promising adjuvant system for yeast vaccines. Vaccine 36, 2314-2320. doi: 10.1016/j.vaccine.2018.03.019

Stephanopoulos, G. (2012). Synthetic biology and metabolic engineering. ACS Synth. Biol. 1, 514-525. doi: 10.1021/sb300094q

Tanska, M., Roszkowska, B., Skrajda, M., and Dabrowski, G. (2016). Commercial cold pressed flaxseed oils quality and oxidative stability at the beginning and the end of their shelf life. J. Oleo Sci. 65, 111-121. doi: 10.5650/jos.ess 15243

Thorbjarnarson, T., and Drummond, J. C. (1935). Occurrence of an unsaturated hydrocarbon in olive oil. Analyst 60, 23-29. doi: 10.1039/an9356000023

Tokuhiro, K., Muramatsu, M., Ohto, C., Kawaguchi, T., Obata, S., Muramoto, N., et al. (2009). Overproduction of geranylgeraniol by metabolically engineered Saccharomyces cerevisiae. Appl. Environ. Microbiol. 75, 5536-5543. doi: 10.1128/AEM.00277-09

Tsoi, K. H., Chan, S. Y., Lee, Y. C., Ip, B. H. Y., and Cheang, C. C. (2016). Shark conservation: an educational approach based on children's knowledge and perceptions toward sharks. PLoS ONE 11:e0163406. doi: 10.1371/journal.pone.0163406

Tsujimoto, M. (1916). A highly unsaturated hydrocarbon in shark liver oil. Ind. Eng. Chem. 8, 889-896. doi: 10.1021/i500010a005

Tsujiwaki, G., Yamamoto, H., and Minami, K. (1995). Manufacture of squalene with Candida famata. Jpn. Kokai Tokkyo Koho JP 7:272.

Tuberoso, C. I., Kowalczyk, A., Sarritzu, E., and Cabras, P. (2007). Determination of antioxidant compounds and antioxidant activity in commercial oilseeds for food use. Food Chem. 103, 1494-1501. doi: 10.1016/j.foodchem.2006.08.014

Uchida, H., Sumimoto, K., Ferriols, V. M. E., Imou, K., Saga, K., Furuhashi, K., et al. (2015). Isolation and characterization of two squalene epoxidase genes from Botryococcus braunii, Race B. PLoS ONE 10:e122649. doi: 10.1371/journal.pone.0122649

United States Department of Agriculture (2018a). Branded Food Products Database. Available online at: https://ndb.nal.usda.gov/ndb/foods/show/ 45087658 ? $\mathrm{fgcd}=\mathrm{andmanu}=$ andformat $=$ and count $=$ andmax $=25$ andoffset $=$ andsort $=$ defaultandorder $=$ ascandqlookup $=$ green $\$+\$$ olivesandds $=$ andq $=$ andqp $=$ and $\mathrm{q}=$ =andqn $=$ and $\mathrm{q}=$ anding $=($ Accessed November 13,2018$)$.

United States Department of Agriculture (2018b). USDA Branded Food Products Database. Available online at: https://ndb.nal.usda.gov/ndb/foods/show/ 45192333 ? $\mathrm{gcd}=$ andmanu=andformat $=$ and count $=$ andmax $=25$ andoffset $=$ andsort $=$ defaultandorder $=$ ascandqlookup $=$ green $\$+\$$ olivesandds $=$ andq $=$ andqp $=$ and $\mathrm{q}=$ and $\mathrm{q}=\mathrm{and} \mathrm{q}=$ anding $=($ Accessed November 13,2018$)$.
United States Department of Agriculture (2018c). National Nutrient Database for Standard Reference Legacy Release. Available online at: https://ndb.nal.usda. gov/ndb/foods/show $/ 20001$ ? $\mathrm{fgcd}=\mathrm{andmanu}=$ andformat $=$ andcount $=$ andmax $=$ 25andoffset $=$ andsort $=$ defaultandorder $=$ ascandqlookup $=$ amaranthandds $=$ and $q \mathrm{t}=$ and $q \mathrm{p}=$ and $\mathrm{a}=$ and $\mathrm{q}=\mathrm{and} \mathrm{q}=$ anding $=($ Accessed November 13, 2018).

Uragami, S., and Koga, H. (1986). Bacterial production of squalene. Jpn. Kokai Tokkyo Koho JP 61, 212-290.

Valachovič, M., and Hapala, I. (2017). "Biosynthetic approaches to squalene production: the case of yeast," in Vaccine Adjuvants, ed C. B. Fox (New York, NY: Humana Press), 95-106.

Wall, M. M. (2010). Functional lipid characteristics, oxidative stability, and antioxidant activity of macadamia nut (Macadamia integrifolia) cultivars. Food Chem. 121, 1103-1108. doi: 10.1016/j.foodchem.2010.01.057

Wang, J. J., Sung, K. C., Yeh, C. H., and Fang, J. Y. (2008). The delivery and antinociceptive effects of morphine and its ester prodrugs from lipid emulsions. Int. J. Pharm. 353, 95-104. doi: 10.1016/j.ijpharm.2007.11.013

Warleta, F., Campos, M., Allouche, Y., Sánchez-Quesada, C., Ruiz-Mora, J., Beltrán, G., et al. (2010). Squalene protects against oxidative DNA damage in MCF10A human mammary epithelial cells but not in MCF7 and MDAMB-231 human breast cancer cells. Food Chem. Toxicol. 48, 1092-1100. doi: 10.1016/j.fct.2010.01.031

Wei, L. J., Kwak, S., Liu, J. J., Lane, S., Hua, Q., Kweon, D. H., et al. (2018). Improved squalene production through increasing lipid contents in Saccharomyces cerevisiae. Biotechnol. Bioeng. 115, 1793-1800. doi: 10.1002/bit.26595

Wejnerowska, G., Heinrich, P., and Gaca, J. (2013). Separation of squalene and oil from Amaranthus seeds by supercritical carbon dioxide. Sep. Purif. Technol. 110, 39-43. doi: 10.1016/j.seppur.2013.02.032

Wen, X., Zhu, M., Hu, R., Zhao, J., Chen, Z., Li, J., et al. (2016). Characterisation of seed oils from different grape cultivars grown in China. J. Food Sci. Technol. 53, 3129-3136. doi: 10.1007/s13197-016-2286-9

WHO (2006). World Health Organization. Available online at: https://www. who.int/vaccine_safety/committee/topics/adjuvants/squalene/questions_and_ answers/en/ (Accessed February 18, 2019).

Wołosik, K., Knaś, M., Zalewska, A., Niczyporuk, M., and Przystupa, A. W. (2013). The importance and perspective of plant-based squalene in cosmetology. $J$. Cosmet. Sci. 64, 59-66.

Xu, W., Chai, C., Shao, L., Yao, J., and Wang, Y. (2016). Metabolic engineering of Rhodopseudomonas palustris for squalene production. J. Ind. Microbiol. Biotechnol. 43, 719-725. doi: 10.1007/s10295-016-1745-7

Yarkoni, E., and Rapp, H. J. (1979). Tumor regression after intralesional injection of mycobacterial components emulsified in 2, 6, 10, 15, 19, 23-hexamethyl$2,6,10,14,18,22$-tetracosahexaene (squalene), 2, 6, 10, 15, 19, 23hexamethyltetracosane (squalane), peanut oil, or mineral oil. Cancer Res. 39, 1518-1520.

Yoon, J., Matsuo, Y., Matsuda, S., Adachi, K., Kasai, H., and Yokota, A. (2007). Rubritalea spongiae sp. nov. and Rubritalea tangerina sp. nov., two carotenoidand squalene-producing marine bacteria of the family Verrucomicrobiaceae within the phylum 'Verrucomicrobia', isolated from marine animals. Int. J. Syst. Evol. Microbiol. 57, 2337-2343. doi: 10.1099/ijs.0.65243-0

Yoon, J., Matsuo, Y., Matsuda, S., Adachi, K., Kasai, H., and Yokota, A. (2008). Rubritalea sabuli sp. nov., a carotenoid-and squalene-producing member of the family Verrucomicrobiaceae, isolated from marine sediment. Int. J. Syst. Evol. Microbiol. 58, 992-997. doi: 10.1099/ijs.0.65540-0

Zhuang, X., and Chappell, J. (2015). Building terpene production platforms in yeast. Biotechnol. Bioeng. 112, 1854-1864. doi: 10.1002/bit.25588

Conflict of Interest Statement: The authors declare that the research was conducted in the absence of any commercial or financial relationships that could be construed as a potential conflict of interest.

Copyright (C) 2019 Gohil, Bhattacharjee, Khambhati, Braddick and Singh. This is an open-access article distributed under the terms of the Creative Commons Attribution License (CC BY). The use, distribution or reproduction in other forums is permitted, provided the original author(s) and the copyright owner(s) are credited and that the original publication in this journal is cited, in accordance with accepted academic practice. No use, distribution or reproduction is permitted which does not comply with these terms. 